J. Dairy Sci. 95:5657-5675

http://dx.doi.org/10.3168/jds.2011-5114

(C) American Dairy Science Association ${ }^{\circledR}, 2012$.

\title{
Effects of lactation and pregnancy on gene expression of endometrium of Holstein cows at day 17 of the estrous cycle or pregnancy
}

\author{
R. L. A. Cerri, ${ }^{\star} †$ I. M. Thompson, ${ }^{\star}$ I. H. Kim,‡ A. D. Ealy, ${ }^{\star}$ P. J. Hansen, ${ }^{\star}$ C. R. Staples, ${ }^{\star}$ J. L. Li, $\S$ \\ J. E. P. Santos, ${ }^{\star}$ and W. W. Thatcher*1 \\ *Department of Animal Sciences, University of Florida, Gainesville 32611 \\ †Faculty of Land and Food Systems, University of British Columbia, Vancouver, BC, Canada V6T 1 Z4 \\ ¥Chungbuk National University, Cheongju, Chungbuk 361-763, Korea \\ $\S$ The Interdisciplinary Center for Biotechnology Research, University of Florida, Gainesville 32610
}

\begin{abstract}
Objectives were to determine effects of lactation and pregnancy on endometrial gene expression on d 17 of the estrous cycle and pregnancy. Heifers $(\mathrm{n}=33)$ were assigned randomly after parturition to lactating (L, n $=17$ ) or nonlactating ( $\mathrm{NL}, \mathrm{n}=16)$ groups. Cows were subjected to an ovulation synchronization program for a timed artificial insemination (TAI); 10 cows in L and 12 in NL were inseminated. Slaughter occurred $17 \mathrm{~d}$ after the day equivalent to TAI, and intercaruncular endometrial tissues were collected. Gene expression was determined by DNA microarray analysis for pregnant $(\mathrm{L}, \mathrm{n}=8 ; \mathrm{NL}, \mathrm{n}=6)$ and noninseminated cyclic (L, $\mathrm{n}=7 ; \mathrm{NL}, \mathrm{n}=4$ ) cows. Differentially expressed genes were selected with a $P$-value $<0.01$ and absolute expression $>40$. In addition, a fold effect $>1.5$ was used as a criterion for genes affected by pregnancy. In total, 210 genes were differentially regulated by lactation (136 downregulated and 74 upregulated), and 702 genes were differentially regulated by pregnancy (407 downregulated and 295 upregulated). The interaction effect of pregnancy and lactation affected 61 genes. Genes up- and downregulated in pregnant cows were associated with several gene ontology terms, such as defense response and interferon regulatory factor, cell adhesion, and extracellular matrix. The gene ontology analyses of up- and downregulated genes of lactating cows revealed terms related to immunoglobulin-like fold, immune response, COMM domain, and non-membrane-bounded organelle. Several genes upregulated by lactation, such as IGHG1, IGLL1, IGK, and TRD, were related to immune function, particularly for B cells and $\gamma \delta \mathrm{T}$ cells. Developmental genes related to limb and neural development and glucose homeostasis (e.g., DKK1, RELN, $P D K 4)$ were downregulated by lactation, whereas an interaction was also detected for RELN. The stated
\end{abstract}

Received November 1, 2011.

Accepted May 29, 2012.

${ }^{1}$ Corresponding author: thatcher@ufl.edu genes associated with immune function and developmental genes expressed in the endometrium affected by lactational state are possible candidate genes for interventions to improve fertility of lactating dairy cows. Key words: endometrium, gene expression, lactation, pregnancy

\section{INTRODUCTION}

The historical decrease in fertility of the lactating dairy cow is probably multifactorial and often associated with high milk production (Lucy, 2001; Santos et al., 2004). The association of sub-fertility and lactation can be regarded as a product of the homeorhetic changes necessary to support milk production, thus directly affecting reproductive tissues. Greater milk production has been associated with physiological changes that can reduce fertility such as accentuated negative energy balance (Wathes et al., 2007), lower concentrations of progesterone and estradiol in plasma (Wiltbank et al., 2006), and disruption of the growth hormone-IGF-1 axis in the liver early postpartum (Kobayashi et al., 1999). Lactating dairy cows have relatively high fertilization rate of around 80 to $90 \%$, but only about $35 \%$ are diagnosed pregnant after $60 \mathrm{~d}$ of gestation (Santos et al., 2004; Sartori et al., 2010). The basic mechanisms that lead to this massive embryonic and fetal loss observed is not clearly understood at the molecular and cellular levels.

Evidence exists to indicate that the uterine environment is compromised in lactating cows. Sartori et al. (2002) observed a greater recovery of good quality embryos from heifers and dry cows than from lactating cows in single ovulating animals. Experiments in which embryos were transferred at around d 7 after estrus often show reduced pregnancy rates when recipients are lactating cows compared with heifers or dry cows (Hasler, 2001; Chagas e Silva et al., 2002; Wilson et al., 2006), indicating that at least the endometrium is in a sub-optimal state in lactating cows. 
Several publications address the controlling mechanisms associated with the generation of a successful pregnancy in ruminants, but evidence is lacking of the molecular changes caused by lactation in reproductive tissues, particularly the endometrium. From fertilization to term, several molecules and systems apparently work in synchrony to receive and maintain the conceptus. Interferon- $\tau$ is synthesized by the trophectoderm cells of the conceptus and is essential for the maintenance of the corpus luteum (CL) during pregnancy (Hansen et al., 1985). Interferon- $\tau$ (IFNT) induces an array of changes in the uterus by promoting the expression of IFN-stimulated genes (ISG; Spencer et al., 2008). In addition to the ISG, genes related to cell remodeling, adhesion and invasion, cell orientation and polarization, angiogenesis, and transporters of glucose and lipids are mostly upregulated by pregnancy and progesterone (Bauersachs et al., 2006; Forde et al., 2010).

Pretheeban et al. (2009) observed a greater expression of HST70 and IFNT in embryos recovered from heifers than from lactating cows, indicating molecular evidence of the effects of lactation in d-7 embryos. The differential gene expression in a d-7 embryo caused by lactation status is likely to be partly mediated by changes in the endometrium. As evidenced by the complexity and synchrony of events occurring in the endometrium in the presence of a conceptus, it is reasonable to believe that homeorhetic changes that come with initiation of milk production would affect one or, more likely, several genes and pathways in the endometrium crucial to a successful pregnancy. A previous report described genome-wide changes in the liver caused by nutritionally induced ketosis (Loor et al., 2007), demonstrating changes in response to alterations in energy balance of lactating dairy cows. It was one of the first reports to address global transcriptome changes with the scope targeted at cows with lactation-related effects as the primary objective of the study. Considering that lactation could potentially affect many genes or functional groups of interest in the endometrium, the use of a microarray fit the goals of the current study. The objectives were to determine the effect of lactation and pregnancy on the endometrium transcriptome. It was also our priority to unveil global changes caused by lactation that could be closely related to the changes induced by the presence of the conceptus in the endometrium.

\section{MATERIALS AND METHODS}

\section{Animals, Housing, Diets, and Treatments}

The University of Florida Institutional Animal Care and Use Committee approved all procedures involving cows in the study. The study was conducted at the University of Florida Dairy Unit. A total of 39 pregnant dairy heifers purchased in New York were enrolled in the study. Mean age of heifers upon arrival was 22 mo (19 to $24 \mathrm{mo}$ ) with an average of $70 \mathrm{~d}$ to the expected due date. Heifers had an average BW of $489.5 \mathrm{~kg}$ (385.5 to $615.9 \mathrm{~kg}$ ) upon arrival and $534.4 \mathrm{~kg}$ (396.4 to 765.9 $\mathrm{kg}$ ) at calving. Heifers were evaluated for pregnancy and vaccinated against leptospirosis (Spirovac L5, Pfizer Animal Health, New York, NY) and major viruses (bovine rhinotracheitis virus, bovine viral diarrhea virus, bovine respiratory syncytial virus, and parainfluenza-3 virus; Cattlemaster 4, Pfizer Animal Health) upon arrival. Cows were vaccinated again at $8 \mathrm{wk}$ before expected date of calving against bovine rotavirus (serotypes G6 and G10), bovine coronavirus, enterotoxigenic strains of Escherichia coli and Clostridium perfringens type C (Scourguard 4KC, Pfizer Animal Health), and against E. coli mastitis (J-Vac, Merial Ltd., Duluth, GA). All heifers were housed in a single sod-based pen with shade at around $3 \mathrm{wk}$ before expected calving and moved after calving to a freestall barn equipped with fans and sprinklers that were automatically turned on when ambient temperature reached $26.7^{\circ} \mathrm{C}$. All cows were fed the same ration $\left(1.51 \mathrm{Mcal}\right.$ of $\mathrm{NE}_{\mathrm{L}} / \mathrm{kg}, 15.2 \%$ $\mathrm{CP}$ ) once daily in the prepartum period. After calving, cows were assigned randomly into 2 treatment groups, nonlactating (NL) and lactating ( $\mathbf{L})$, and moved to the freestall facility. The NL heifers were dried off immediately (i.e., not milked) after calving, whereas the L cows were milked twice daily.

Rectal temperatures, BW, BCS, ovarian ultrasound examinations, milk production data, milk samples for measurement of protein and fat, and blood samples used for measurement of NEFA, BHBA, BUN, glucose, and progesterone in plasma were collected. Analysis and detailed discussion are presented in the companion paper (Thompson et al., 2012). Briefly, rectal temperature was greater in L than NL $(38.4 \pm 0.04>$ $38.2 \pm 0.04^{\circ} \mathrm{C} ; P<0.01$ ), whereas BW and BCS were not different between $\mathrm{L}$ and NL $(P>0.10)$. The NL cows resumed estrous cycles earlier $(P<0.04)$ than $\mathrm{L}$ cows $(26.4 \pm 2.01$ vs. $34.7 \pm 3.09$ DIM; hazard ratio $=$ $0.464)$. Mean milk production and milk fat and protein percentages in $\mathrm{L}$ cows were was $23.7 \pm 0.20 \mathrm{~kg}, 3.44$ $\pm 0.24 \%$, and $2.98 \pm 0.04 \%$, respectively. Mean concentration of NEFA in plasma did not differ between treatments $(P>0.10)$. Cows in $\mathrm{L}$ had greater $(P<$ $0.01)$ concentrations of BHBA (4.90 \pm 0.23 vs. 2.97 $\pm 0.24 \mathrm{mg} / \mathrm{dL})$ and BUN $(11.64 \pm 0.32$ vs. $6.5 \pm 0.33$ $\mathrm{mg} / \mathrm{dL}$ ) throughout the postpartum period than NL cows. Concentrations of glucose in plasma were lower $(P<0.01)$ for $\mathrm{L}$ compared with NL cows $(74.0 \pm 1.12$ vs. $79.9 \pm 1.17 \mathrm{mg} / \mathrm{dL})$. 
Heifers were checked for health and reproductive disorders during the entire study and treated according to the standard operational procedures of the dairy. Only cows with a clinically healthy reproductive tract at the initiation of the synchronization protocols were included in the analysis. Four cows were removed from the study: 2 had persistent uterine problems (adhesion and pyometra) and 2 were down cows that were eventually euthanized. Of the heifers analyzed for the study, the NL group had 2 cases of mastitis soon after calving and 1 case of lameness. In the L cows, 2 cows developed retained placenta followed by clinical metritis, 1 cow had only a retained placenta, and 1 cow was diagnosed with pyometra (i.e., treated and was normal at the time of synchronization).

The NL cows were fed a far-off dry cow ration $(1.45$ Mcal of $\mathrm{NE}_{\mathrm{L}} / \mathrm{kg}, 12.2 \% \mathrm{CP}$ ) once per day to meet maintenance requirements. Cows in the $\mathrm{L}$ treatment were fed a TMR (1.65 Mcal of $\mathrm{NE}_{\mathrm{L}} / \mathrm{kg}$ and $16.5 \% \mathrm{CP}$ ) twice daily to allow ad libitum access to feed and water. Complete dietary and chemical composition of the diets is given in detail in the companion paper (Thompson et al., 2012). Of the 39 pregnant heifers enrolled, 4 were excluded from the experiment because of death or because they failed to complete the study due to occurrence of reproductive disorders. Thus, 35 cows were used to complete the study.

\section{Study Design}

The $\mathrm{L}(\mathrm{n}=18)$ and NL $(\mathrm{n}=17)$ groups were managed in separate pens. All cows were placed on a presynchronization/synchronization reproductive management protocol. However, only 10 cows in the L group and 12 in the NL group were bred by timed AI (TAI), and the noninseminated cows were considered as cyclic $(\mathrm{L}, \mathrm{n}=$ $8 ; \mathrm{NL}, \mathrm{n}=5$ ). Cows in each treatment were randomly assigned to be bred by TAI or not TAI. Presynch was initiated with an i.m. injection of GnRH $(100 \mu \mathrm{g}$ of Cystorelin, Merial Ltd.) at $44 \pm 3 \mathrm{~d}$ after parturition, followed $7 \mathrm{~d}$ later by an injection of $\mathrm{PGF}_{2 \alpha}(25 \mathrm{mg}$ of Lutalyse, Pfizer Animal Health). At 12 d after PGF $_{2 \alpha}$, the ovulation synchronization protocol was initiated by administering $100 \mu \mathrm{g}$ of $\mathrm{GnRH}$ and inserting an intravaginal progesterone insert (CIDR; Easi-Breed, Pfizer Animal Health) for $5 \mathrm{~d}$. Cows received an injection of $\mathrm{PGF}_{2 \alpha}(25 \mathrm{mg})$ at the time of CIDR removal and another $\mathrm{PGF}_{2 \alpha}$. $(25 \mathrm{mg})$ injection $12 \mathrm{~h}$ later. Then, $\mathrm{GnRH}$ $(100 \mu \mathrm{g})$ was injected $72 \mathrm{~h}$ after the first $\mathrm{PGF}_{2 \alpha}$ injection, and cows intended to become pregnant underwent TAI at the time of the last GnRH injection and $12 \mathrm{~h}$ later (i.e., a.m. and p.m.). On d 17 after GnRH-TAI, inseminated and noninseminated (i.e., cyclic) cows were slaughtered (Figure 1).

\section{Tissue Collection}

All cows were slaughtered in the abattoir of the Department of Animal Sciences at the University of Florida. Reproductive tracts were collected within 10 min of slaughter. The uterine horn ipsilateral to the $\mathrm{CL}$ was cut along the antimesometrial border and the entire uterine horn was exposed. If the cow was inseminated, the uterine horn was examined for presence of a conceptus. Intercaruncular tissues were collected separately for RNA analyses. Endometrial tissue was

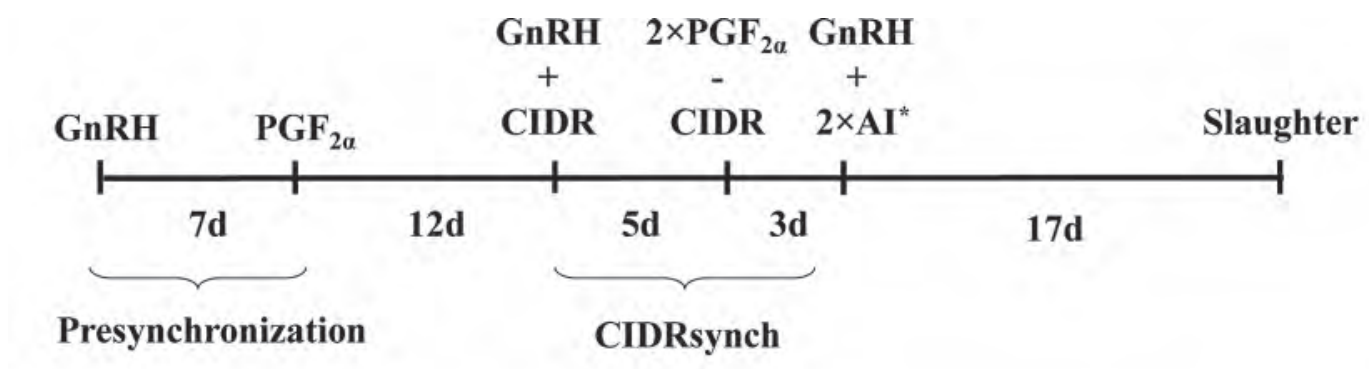

\begin{tabular}{|c|c|c|}
\hline DIM $44 \pm 3$ & $71 \pm 3$ & $88 \pm 3$ \\
\hline \multicolumn{3}{|c|}{ Ultrasound and blood sampling } \\
\hline & nlactati & \\
\hline
\end{tabular}

Figure 1. Design of the synchronization protocol and activities after initiation of controlled internal drug-release device (CIDR) containing $1.38 \mathrm{~g}$ of progesterone. ${ }^{*}$ Only cows intended to become pregnant underwent timed AI. PP = days postpartum; GnRH $=$ injection of gonadotropin releasing hormone; $\mathrm{PGF}_{2 \alpha}=$ prostaglandin $\mathrm{F}_{2 \alpha}$ injection; CIDRsynch = protocol for synchronization of ovulation. 
dissected from the myometrium and sections of intercaruncular tissues were frozen in liquid nitrogen.

\section{RNA Isolation and Array Hybridization}

The RNA from intercaruncular endometrial tissues was extracted using TRIzol reagent (Invitrogen Corp., Carlsbad, CA) according to instructions provided by the manufacturer. Samples were purified (PureLink Microto-Midi kit, Invitrogen Corp.) and RNA concentration, purity, and integrity were determined (Agilent 2100 Bioanalyzer, Agilent Technologies Inc., Santa Clara, CA). Samples were placed in aliquots and stored at $-80^{\circ} \mathrm{C}$. Amplification and biotin labeling were performed with an initial $200 \mathrm{ng}$ of RNA by using MessageAmp III (Applied Biosystems Inc., Foster City, CA) according to the manufacturer's guidelines. Samples were then tested in the Bioanalyzer for quality determination (all samples had an RNA integrity number >7.5) and subsequently submitted for fragmentation and hybridization to the bovine microarray (Affymetrix GeneChip Bovine Genome Array, Affymetrix Inc., Santa Clara, CA). The array contains approximately 24,000 probe sets that represent more than 23,000 bovine transcripts and approximately 19,000 UniGene clusters. The Affymetrix GeneChip uses 25-mer oligonucleotides to measure the abundance of mRNA transcripts, and each probe set contains 11 probe-pair replicates. Each probe is designed to hybridize to a specific sequence, and a mismatch probe that has one mismatched nucleotide allows for accurate quantitation and subtraction of background fluorescence and hybridization of nonspecific sequences.

\section{Quantitative, Real-Time, Reverse Transcription-PCR}

Total RNA was isolated as previously described. Then, the RNA samples (50 ng/reaction) were treated with RNase-free DNase I (New England BioLabs, Ipswich, MA) for $15 \mathrm{~min}$ at $37^{\circ} \mathrm{C}$, heat denatured $\left(75^{\circ} \mathrm{C}\right.$ for $10 \mathrm{~min}$ ), and then reverse transcribed using High Capacity cDNA Reverse Transcription Kit and random hexamers (Applied Biosystems). Primers specific for the selected transcripts were designed using Primer Express v2.0 (Applied Biosystems) and are shown in Table 1. Amplification efficiencies were similar between all primer sets as determined by using 1:4 serial dilutions of standard endometrial RNA samples. Quantitative, reverse transcription (qRT)-PCR was completed using SYBR Green PCR Master Mix (Applied Biosystems) with the following cycling conditions: $95^{\circ} \mathrm{C}$ for $10 \mathrm{~min} ; 40$ cycles of $95^{\circ} \mathrm{C}$ for $15 \mathrm{~s}$ and $60^{\circ} \mathrm{C}$ for $1 \mathrm{~min}$; 55 to $95^{\circ} \mathrm{C}$ for dissociation. Each PCR was performed in triplicate, and the specificity of amplification was verified by melting curve analysis. A reaction lacking reverse transcriptase was included to verify the absence of genomic DNA contamination in reactions.

\section{Differentially Expressed Genes}

Differentially expressed transcripts caused by lactation status were determined using the $P=0.01$ and a cut-off $\geq 40$ absolute expression (40 being the expression value for the oxytocin receptor gene, $O X T R$ ). The criteria to determine the effects of pregnancy were similar to those for effects of lactation $(P=0.01)$, but included a $\geq 2.0$ - and $\geq 1$.5-fold effect for up- and downregulated transcripts, respectively, when examining the ratio of pregnant:cyclic or cyclic:pregnant. If a gene was represented in the array by more than one transcript, the mean signal ratio was calculated. The web tool DAVID (http://david.abcc.ncifcrf.gov/home.jsp) used for the analysis was based on correspondent human orthologs, and Homo sapiens were used as background for comparison. The use of human correspondent genes greatly increased the number of annotated genes assigned to terms of biological importance and, therefore, of relevant functional groups and biological processes, molecular function, and cellular components related to pregnancy and lactation status.

\section{Statistical Analyses}

Gene expression statistical tests were performed primarily using Bioconductor statistical software (http:// www.bioconductor.org/), which is an open source and development software packet for analysis of microarray throughput data that is based primarily on the $\mathrm{R}$ programming language (Gentleman et al., 2004). All array data were first preprocessed and normalized using the Affy package (Bolstad et al., 2003). Raw data were normalized by the GeneChip Robust Multichip Analysis (GCRMA) approach (Bolstad et al., 2003), and the probe set's detection call was estimated by using the Wilcoxon signed rank-based algorithm. Probe sets that were absent in all the study samples were removed from further analyses. For each gene represented on the microarray, a 2-way ANOVA was conducted to identify genes that were regulated differentially for lactation (NL and L), reproductive status (cyclic and pregnant), and the interaction of lactation and reproductive status. A linear modeling approach and the empirical Bayes statistics as implemented in the Limma package (Smyth, 2004) of the R software were employed for differential expression analysis. Differentially expressed genes were ranked by $P$-values, and genes with $P$ values $\leq 0.01$ were considered differentially expressed. Hierarchical clustering of the data was computed on 
Table 1. Gene primers used for quantitative reverse transcription-PCR

\begin{tabular}{|c|c|c|c|}
\hline Gene name (symbol) & GenBank ID & Primer & Sequence $\left(5^{\prime}\right.$ to $\left.3^{\prime}\right)$ \\
\hline \multirow[t]{2}{*}{ Aquaporin $4(A Q P 4)$} & NM_181003 & Forward & GGTGGAGCAGAAAAGCCACTA \\
\hline & & Reverse & TCGCGATGCTGAGTCCAA \\
\hline \multirow[t]{2}{*}{ BCL2-associated athanogene 3 (BAG3) } & NM_001082471 & Forward & GGCTGGGAAATCAAGATCGA \\
\hline & & Reverse & GTCGTGGTGCGGTTGTTGT \\
\hline \multirow{2}{*}{ Cytochrome P450, family 39, subfamilyA, polypeptide 1 (CYP39A1) } & NM_001098938 & Forward & GCTGGCTCTGTTGGAGATTCA \\
\hline & & Reverse & CCACCAAGTGGAGAGAACTCTGT \\
\hline \multirow[t]{2}{*}{ Dickkopf homolog 1 (DKK1) } & XM_580572 & Forward & GTTTGAGGGAGGCAGCAAGTA \\
\hline & & Reverse & CAGTATTCCCGATCCCCAAGA \\
\hline \multirow[t]{2}{*}{ Glutathione S-transferase pi (GSTP1) } & BC102704 & Forward & CTCCCCCGAGCACATGAA \\
\hline & & Reverse & GCTGCAAGCCCTCACTGTTT \\
\hline \multirow{2}{*}{ Immunoglobulin heavy constant gamma 1 (IGHG1) } & DQ452014 & Forward & TCCCACATGCAAACCATCAC \\
\hline & & Reverse & CGGTGGGAAGATGAAGACAGA \\
\hline \multirow[t]{2}{*}{ Lectin, glalactoside-binding, soluble, 1 ( $L G A L S 1)$} & NM_175782 & Forward & CAACCTGTGCCTCCACTTCA \\
\hline & & Reverse & TTGCTGTTACACACGATGGTGTT \\
\hline \multirow[t]{2}{*}{ Pyruvate dehydrogenase kinase, isozyme 4 (PDK4) } & BC150114 & Forward & CAGGTGGACAGGGCAGTCTAG \\
\hline & & Reverse & TCСТCСТTTTCСАTСТTТСТTСТTT \\
\hline \multirow{2}{*}{ Placental growth factor $(P l G F)$} & NM_173950 & Forward & GTAACCAGTCCCTCGGAAGAGA \\
\hline & & Reverse & AGGTAACTGAGAACGTGACGGTAAT \\
\hline \multirow[t]{2}{*}{ Reelin $(R E L N)$} & XM_002704085 & Forward & CCACAGGCCTTAATACAACAACAG \\
\hline & & Reverse & GGGTCTGAGTAACTATAGCGACATGA \\
\hline \multirow[t]{2}{*}{ S100 calcium binding protein A4 (S100A4) } & BC103192 & Forward & TGGCATACCCCCTGGAGAA \\
\hline & & Reverse & CCTCCTTGCCCGAGTACTTG \\
\hline \multirow[t]{2}{*}{ T-cell receptor delta chain $(T R D)$} & XM_603355 & Forward & TCCAATGGACGGGTGTTAAAG \\
\hline & & Reverse & TGAGACAGAGCGGCAGAAGA \\
\hline \multirow[t]{2}{*}{ Follistatin $(F S T)$} & BC133637 & Forward & GCGAGTGTGCCATGAAGGA \\
\hline & & Reverse & TTGCAAGATCCGGAGTGCTT \\
\hline \multirow[t]{2}{*}{ Tumor necrosis factor receptor superfamily, member 1 (TNFRSF1A) } & BC113278 & Forward & AGAACTCAGCAAGGCGACTTG \\
\hline & & Reverse & CAAAGATGGCTTATCTACTGCGAAA \\
\hline \multirow[t]{2}{*}{ Glyceraldehyde-3-phosphate dehydrogenase $(G A P D H)$} & NM_001034034 & Forward & ACCCAGAAGACTGTGGATGG \\
\hline & & Reverse & CAACAGACACGTTGGGAGTG \\
\hline
\end{tabular}


log-transformed and normalized data using complete linkage and Pearson correlation distances.

The qRT-PCR results were analyzed using the mean threshold cycle $(\mathbf{C T})$ for each transcript. The CT was calculated and normalized for the housekeeping gene $G A P D H$ to generate delta $(\Delta) \mathrm{CT}$ values. Changes in relative abundance of specific transcripts were calculated by using the delta delta $(\Delta \Delta)$ CT method (Cooke et al., 2009). Differences were analyzed using the PROC MIXED procedure of SAS software (version 9.2; SAS Institute Inc., Cary, NC), with the model including the effects of pregnancy, lactation, and interaction, and cow nested within treatment as the random error.

To understand more about cellular mechanisms among the physiological states, we performed functional enrichment analyses (i.e., application of pathway and gene ontology programs) for selected statistically significant genes. The biological significance of all the annotated significant genes was determined using the web tool DAVID and Pathway Studio software from Ariadne Genomics Inc. (http://www.ariadnegenomics.com). The Fisher exact probability test was used to identify statistically overrepresented gene ontology (GO; http://www.geneontology.org/) terms or pathways.

\section{RESULTS}

After we excluded cows that did not conceive in the TAI/pregnant groups (i.e., $2 \mathrm{~L}$ and $6 \mathrm{NL}$ ) and cows with pyometra (i.e., $1 \mathrm{~L}$ ) and regressed CL (i.e., NL), 7 cyclic L, 8 pregnant L, 4 cyclic NL, and 6 pregnant NL cows were utilized for microarray analyses. All the noninseminated (i.e., cyclic) animals were included in the analysis, but only those inseminated animals that had a conceptus recovered were used. One cyclic cow from the NL treatment was removed from the analysis because of luteolysis before slaughter. In total, 6 of 12 (i.e., $50 \%$ ) cows inseminated in the NL group and 8 of 10 (i.e., 80\%) in the L group were pregnant on $\mathrm{d} 17$. The distribution of animals that entered the microarray analysis was $10 \mathrm{NL}$ cows (4 cycling and 6 pregnant) and $15 \mathrm{~L}$ cows (7 cycling and 8 pregnant).

\section{Array Hybridization and Quality Control}

The Affymetrix microarray contained a series of hybridization controls and housekeeping genes to verify the proper function of the array. The visual observation of the RNA degradation plot and density plot indicated proper hybridization of the sample RNA into the chip in all cows (data not shown). Hybridization controls are used to assess both chip quality and hybridization efficiency and are used to standardize signal intensity for the chip. The hybridization controls and labeling controls were consistent across the 25 endometrium arrays within each hybridization control (AFFXr2-P1-CREavg; AFFX-r2-Ec-bioD-avg; AFFX-r2-Ec-bioC-avg; AFFX-r2-Ec-bioB-avg) and labeling control (AFFX-r2Bs-dap-avg; AFFX-r2-Bs-thr-avg; AFFX-r2-Bs-pheavg; AFFX-r2-Bs-lys-avg) probe sets. Overall average expressions for hybridization control and labeling control were 2,549 and 5, respectively. Density plots indicated that arrays samples of endometrium were homogeneous. The Box plots of the endometrial arrays before and after GCRMA normalization were similar. Average expressions were GAPDH, 7,200; actin, 600; cyclophilin B, 8,700. Average expression of genes studied was 1,700. Raw expression values were normalized by the GCRMA ( $\log _{2}$-transformed). Values presented are untransformed and presented as least squares means and standard errors. The threshold detection level was 40 .

\section{Genes Differentially Expressed Between Pregnant and Nonpregnant Cows}

A cluster dendrogram illustrates the arrays with closest correlations based on global gene expression. It is worthwhile to note the separation between arrays from pregnant and cyclic cows (Figure 2). In total, 985 transcripts (Supplement 1; http://www.journalofdairyscience.org/) were differentially expressed in the endometrium of pregnant and cyclic cows, with 431 transcripts upregulated (i.e., increased expression) and 554 downregulated (i.e., decreased expression) in pregnant cows. In total, 702 transcripts $(71 \%$; 295 up- and 407 downregulated genes) corresponded to genes with known or inferred function and these genes, therefore, were used for the GO and pathway analyses. Summaries of the 10 GO terms that best represented the cluster of biological processes of greatest significance that were upregulated and downregulated are shown in Figure 3 and Figure 4, respectively. Defense response (GO:0006952) and interferon regulatory factor (IPR001346) were the terms with the greatest upregulated response, whereas cell adhesion (GO:0007155) and extracellular matrix (GO:0031012) were the terms with the greatest downregulated response. A list of the genes that belong to each GO term (cluster) is shown in Supplement 2 (http://www.journalofdairyscience. $\operatorname{org} /)$.

\section{Genes Differentially Expressed Between Lactating and Nonlactating Cows}

In total, 277 transcripts (Supplement 3; http://www. journalofdairyscience.org/) were differentially expressed 


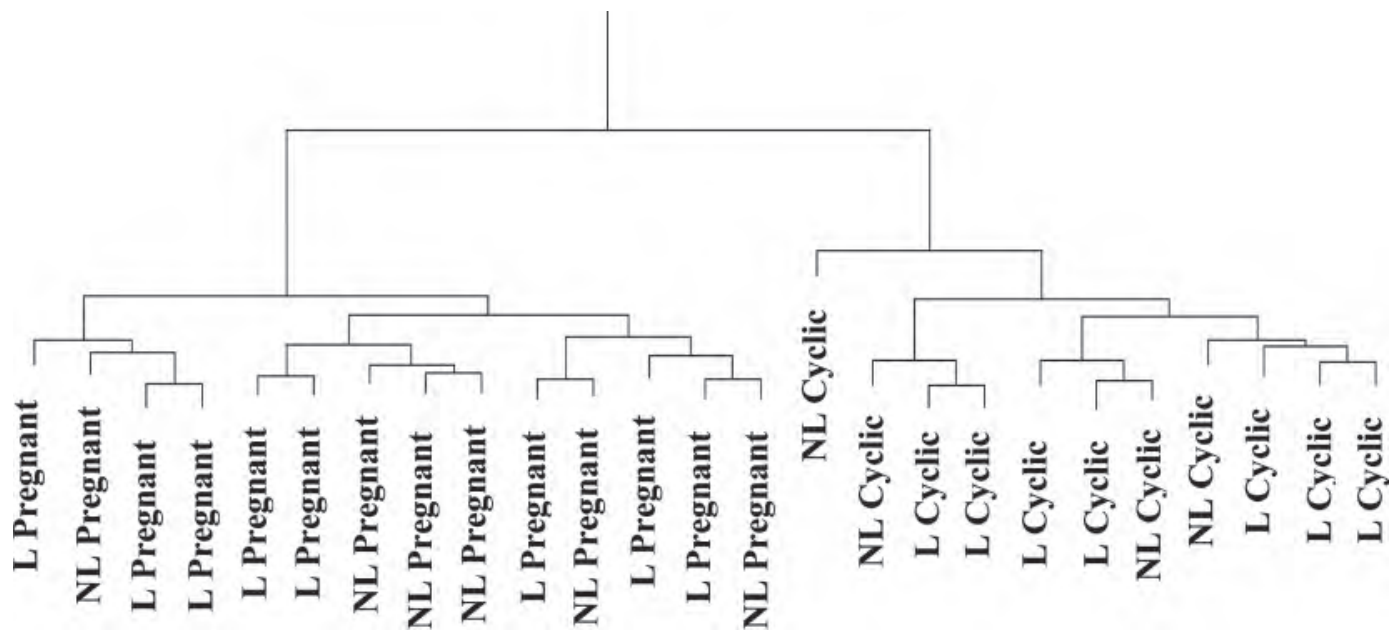

Figure 2. Cluster dendrogram of the individual microarrays. $\mathrm{L}=$ lactating, NL = nonlactating.

in the endometrium of lactating and nonlactating cows, with 96 transcripts upregulated (i.e., increased expression) and 181 downregulated (i.e., decreased expression) in lactating cows. In total, 210 transcripts (76\%; 74 upregulated and 136 downregulated genes) corresponded to genes with known or inferred function and these, therefore, were used for GO and pathway analyses. Summaries of the 10 GO terms that best rep- resented the cluster of biological processes of greatest significance that were upregulated and downregulated are shown in Figure 5 and Figure 6, respectively. Immunoglobulin-like fold (IPR013783) and immune response (GO:0006985) were the terms of particular biological interest that were the most significant upregulated pathways, whereas COMM domain (IPR017920) and non-membrane-bounded organelle (GO:0043228) were

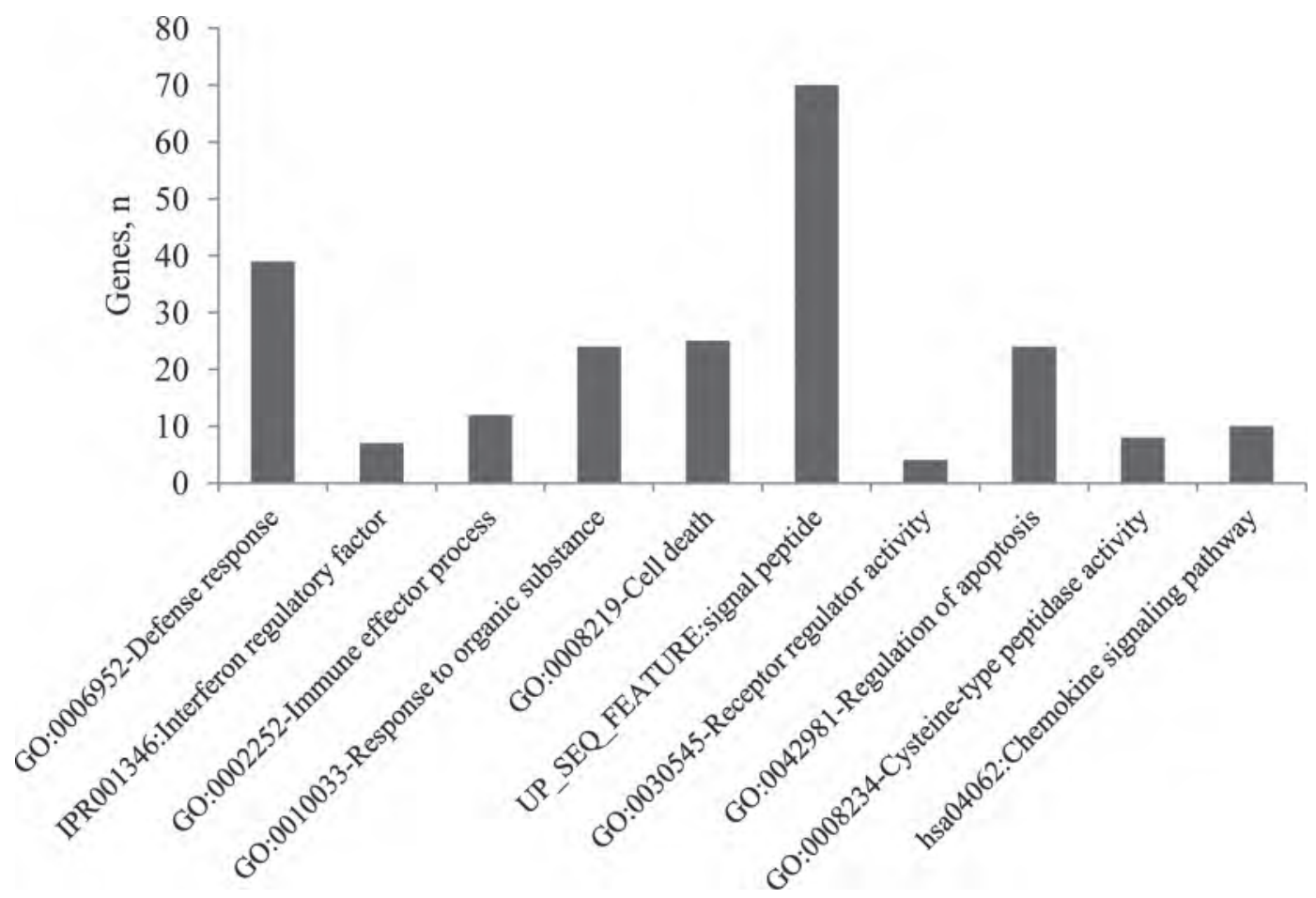

Figure 3. Enriched gene ontology (GO; http://www.geneontology.org/) terms for genes upregulated in the endometrium of pregnant cows. Terms shown are those that best represented the terms within each cluster. Order of significance is displayed from left to right of the figure (Supplement 5; http://www.journalofdairyscience.org/). All bars represent an enrichment score for the cluster $\geq 1.3$ (Supplement 2; http://www. journalofdairyscience.org/). 


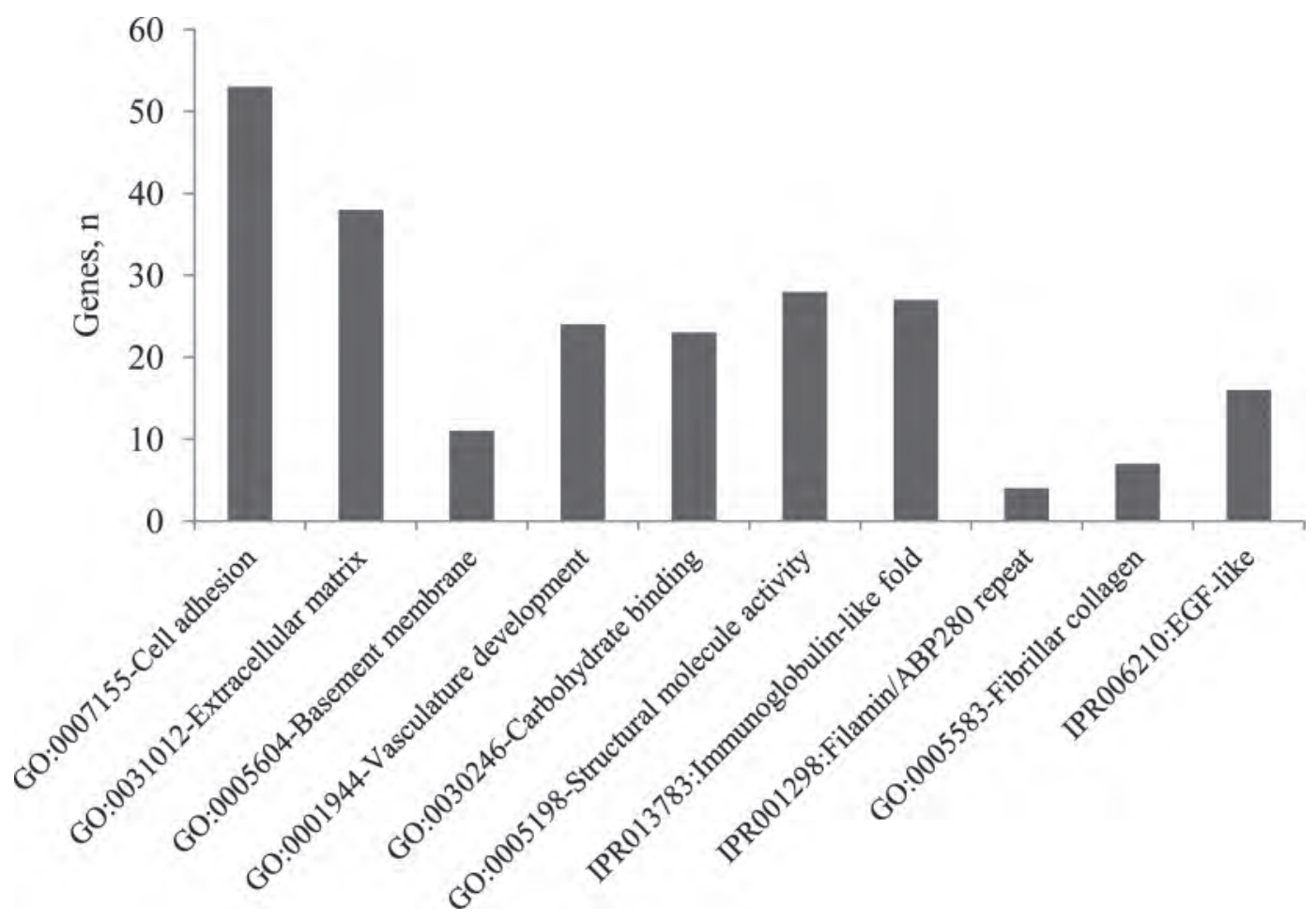

Figure 4. Enriched gene ontology (GO; http://www.geneontology.org/) terms for genes downregulated in the endometrium of pregnant cows. Terms shown are those that best represented the terms within each cluster. Order of significance is displayed from left to right of the figure (Supplement 5). All bars represent an enrichment score for the cluster $\geq 1.3$ (Supplement 2; http://www.journalofdairyscience.org/).

the most downregulated terms related to lactation. A list of the genes that belong to each GO term (cluster) is shown in Supplement 2 (http://www.journalofdairyscience.org/).

\section{Interaction Between Pregnancy and Lactation}

In total, 75 transcripts (Supplement 4; http://www. journalofdairyscience.org/) were affected by the interaction between pregnancy and lactation. Sixty-one transcripts $(81 \%)$ corresponded to genes with known or inferred function, and these were used for the GO and pathway analyses. A summary of GO terms (Figure 7) is presented with the 10 terms that best represented the cluster of biological processes of greater significance. Protein catabolic process (GO:0030163) and GTPase regulatory activity (GO:0030695) were the terms with the most significance related to the interaction between pregnancy and lactation. A list of the genes that belong to each GO term (cluster) is shown in Supplement 2 (http://www.journalofdairyscience.org/).

\section{Validation by Real-Time $q R T-P C R$}

Fourteen genes were selected for mRNA validation based on biological significance and magnitude of differ- ential expression caused by lactation and pregnancy. In $80 \%$ of the cases (12 out of 15), the array hybridization results were confirmed by qRT-PCR. The magnitude of the differences was also similar between the array and qRT-PCR methods (Figure 8).

\section{Pathway Analysis}

Analysis using the Pathway Studio software detected 2 major pathways of biological significance that contained genes differentially expressed due to lactation and pregnancy. These were related to adherens junction assembly (Figure 9) and adipocytokine signaling (Figure 10), which contained upstream and downstream genes that affected regulation of cell adhesion as well as glucose and FA metabolism. In addition, the chemokine signaling pathway from the KEGG (Kyoto Encyclopedia of Genes and Genomes) pathway analysis (Figure 11) had several genes differentially expressed by pregnancy.

\section{DISCUSSION}

The effect of lactation and pregnancy on the global gene expression profile in the intercaruncular endometrium of Holstein dairy cows was the main goal 


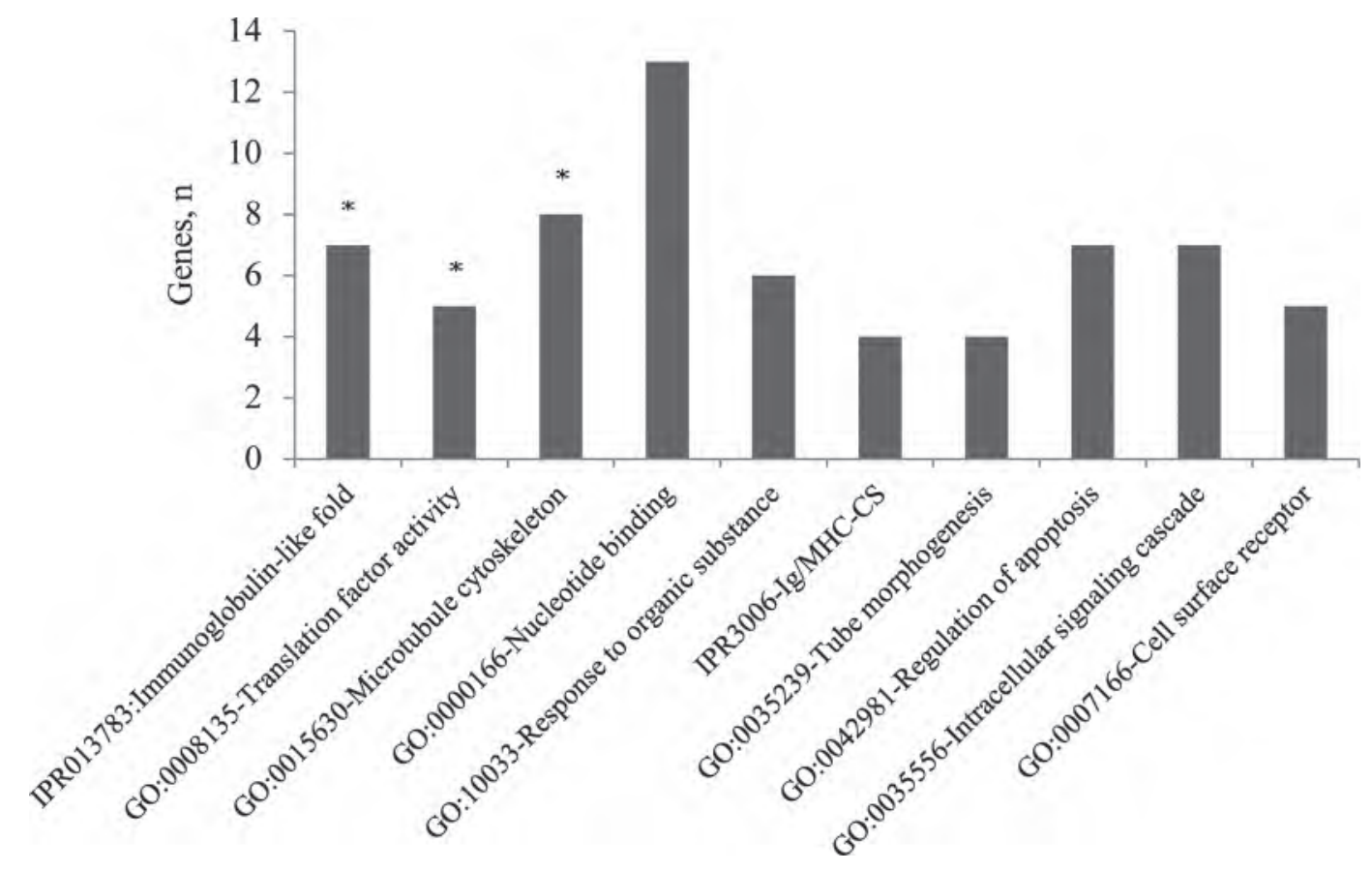

Figure 5. Enriched gene ontology (GO; http://www.geneontology.org/) terms for genes upregulated in the endometrium of lactating cows. Terms shown are those that best represented the terms within each cluster. Order of significance is displayed from left to right of the figure (Supplement 5; http://www.journalofdairyscience.org/). Above each bar, ${ }^{*}$ denotes an enrichment score for the cluster $\geq 1.3$ (Supplement 2; http://www.journalofdairyscience.org/).

of the current study. Although the many changes in gene expression related to pregnancy seen here were in agreement with previous reports on effects of pregnancy status on the endometrium during d 16 to 18 of the estrous cycle or pregnancy (Bauersachs et al., 2006; Spencer et al., 2008), the present study identified genes whose expression in the endometrium was altered by lactation and others whose expression was compromised or changed in response to pregnancy in lactating cows. Thus, results support the idea that reduced fertility in lactating dairy cows is due, at least in part, to changes in endometrial function and in the response of the endometrium to pregnancy signals from the conceptus. Other experiments that involve transfer of embryos into the oviduct (Rizos et al., 2010) or uterus (Chagas e Silva et al., 2002; Wilson et al., 2006) also support the idea that the reproductive tract of the lactating cow is compromised with ability to support embryonic development. The genes and gene ontologies so affected by lactation may be important targets for therapeutic, genetic, or nutritional strategies to improve fertility in the lactating dairy cow.

Live animal performance data and data related to CL function, blood metabolites, and progesterone are not described in the current study. The use of this model as a platform for future studies aiming to investigate lactation effects was satisfactory to provide the necessary conditions to test our initial hypothesis. The results and considerations of the platform are described and discussed in detail in the companion paper (Thompson et al., 2012).

\section{Immune Response}

Changes in immune response clearly reflect the signaling by IFN- $\tau$ with profound effects on endometrial gene expression. In sheep, around $8 \%$ of the analyzed genes $(1,274$ out of 15,634$)$ were deemed to be IFN- $\tau$ responsive (Chen et al., 2007). Reports (Bauersachs et al., 2006; Spencer et al., 2008; Forde et al., 2011) have described several genes and the complexity to understand the variety of functions that are affected by different stages of the estrous cycle and the presence of the conceptus. The IFN- $\tau$ synthesized by trophectoderm is the main signal needed to block the $\mathrm{PGF}_{2 \alpha}$ cascade (Thatcher et al., 1989; Spencer and Bazer, 2004), but it also promotes the regulation of a great number of ISG involved in cell adhesion, angiogenesis, tissue remodeling, immune function, metabolic processes, and others (Bauersachs et al., 2006; Chen et al., 2007 Spencer et al., 2008; Mansouri-Attia et al., 2009; Forde et al., 2010; Walker et al., 2010). The current study detected 4,033 transcripts differentially expressed due to pregnancy, of which 985 transcripts 


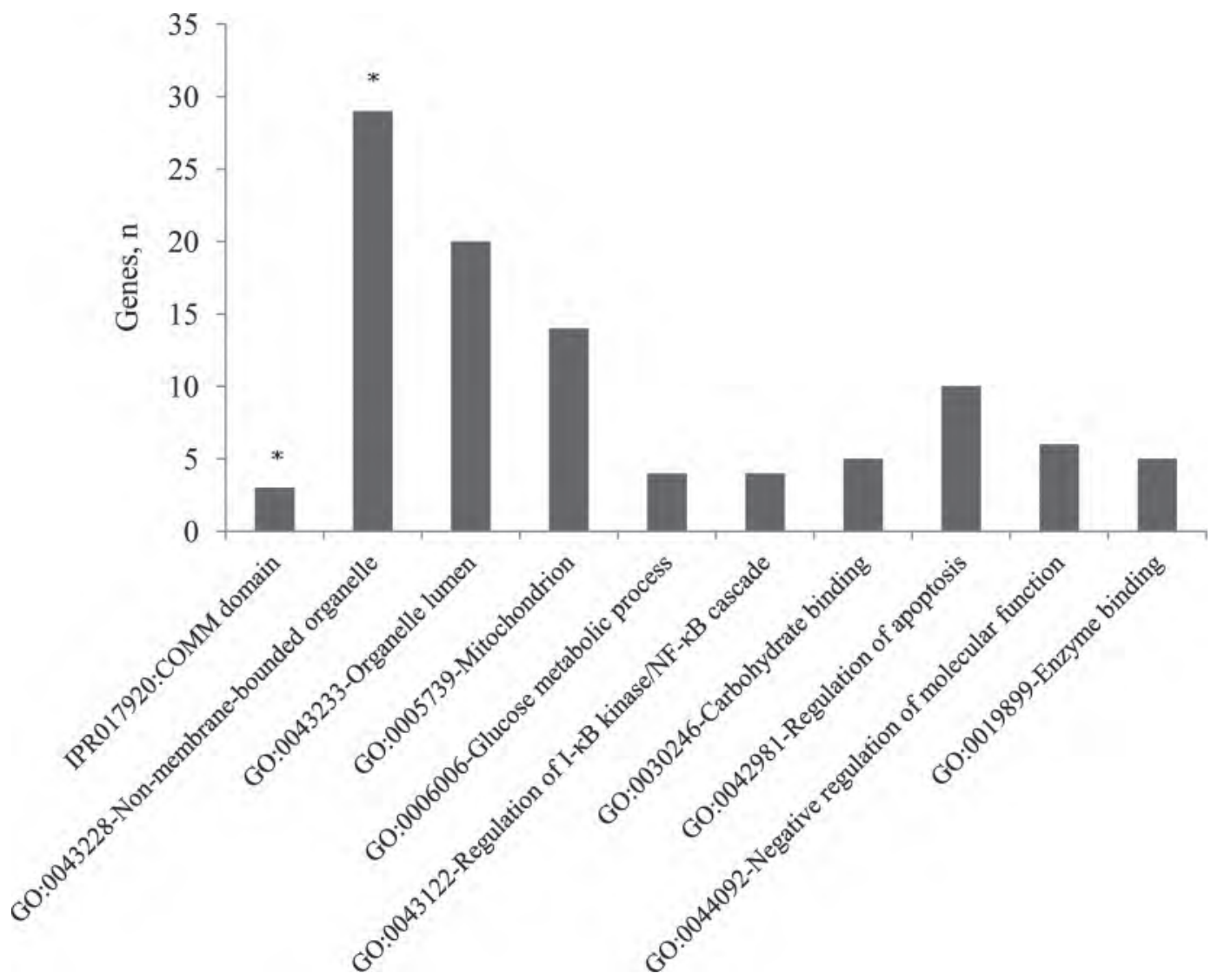

Figure 6. Enriched gene ontology (GO; http://www.geneontology.org/) terms for genes downregulated in the endometrium of lactating cows. Terms shown are those that best represented the terms within each cluster. Order of significance is displayed from left to right of the figure (Supplement 5; http://www.journalofdairyscience.org/). Above each bar, ${ }^{*}$ denotes an enrichment score for the cluster $\geq 1.3$ (Supplement 2; http://www.journalofdairyscience.org/).

had a fold increase $>1.5$ for downregulated transcripts and $>2.0$ for upregulated transcripts that encoded for 702 genes of known or inferred functions. The results from the GO analyses (Supplements 4 and 5; http:// www.journalofdairyscience.org/) show an upregulation of many genes related to the immune system such as defense response (GO:0006952), interferon regulatory factor (IPR001346), and immune effector process (GO:0002252). A great portion of these genes (the vast majority upregulated by pregnancy) were in fact ISG genes, such as MX1, MX2, B2M, ISG12, ISG15, ISG20, IFN regulatory factors (IRF1, IRF3, IRF5, IRF6, IRF', IRF8, IRF9), IFIH1, chemokines (CCL2, CCL8, CCL11, CXCL2, CXCL10, CCR 7), STAT1, and STAT2, with many of them previously described in sheep (Spencer et al., 2008).

Collectively, many of these differentially expressed ISG genes play an important role on uterine receptivity and implantation, including in species such as humans and mouse (Li et al., 2001; Austin et al., 2003). However, it is uncertain whether all immune-responsive genes represent a necessary requirement for maintenance and development of the conceptus or are also conceptus-induced specific effects to regulate maintenance of the CL in pregnancy. It is also not clear whether induction of IFN-responsive genes in the uterus is a general feature of pregnancy (Roberts et al., 2008; Bazer et al., 2009).

The genes that encode for the Fc fragment of IgG (FCGRT), T-cell receptor delta chain $(T R D)$, immunoglobulin heavy constant gamma 1 (IGHG1), and immunoglobulin light chain, lambda gene cluster (IGLL1) were all upregulated (approximately 2- to 8-fold increase) by lactation in the current study and provided some new insight into how lactation could affect the normal mechanism of early embryonic development. Except for TRD, these genes are related to immunoglobulins and indicate a possible increase in Blymphocyte activity or an increase in the endometrial B-lymphocyte population in lactating dairy cows. None of these immunoglobulin genes were affected by pregnancy and no interaction with lactation was observed, indicating a novel effect on endometrial gene expression 


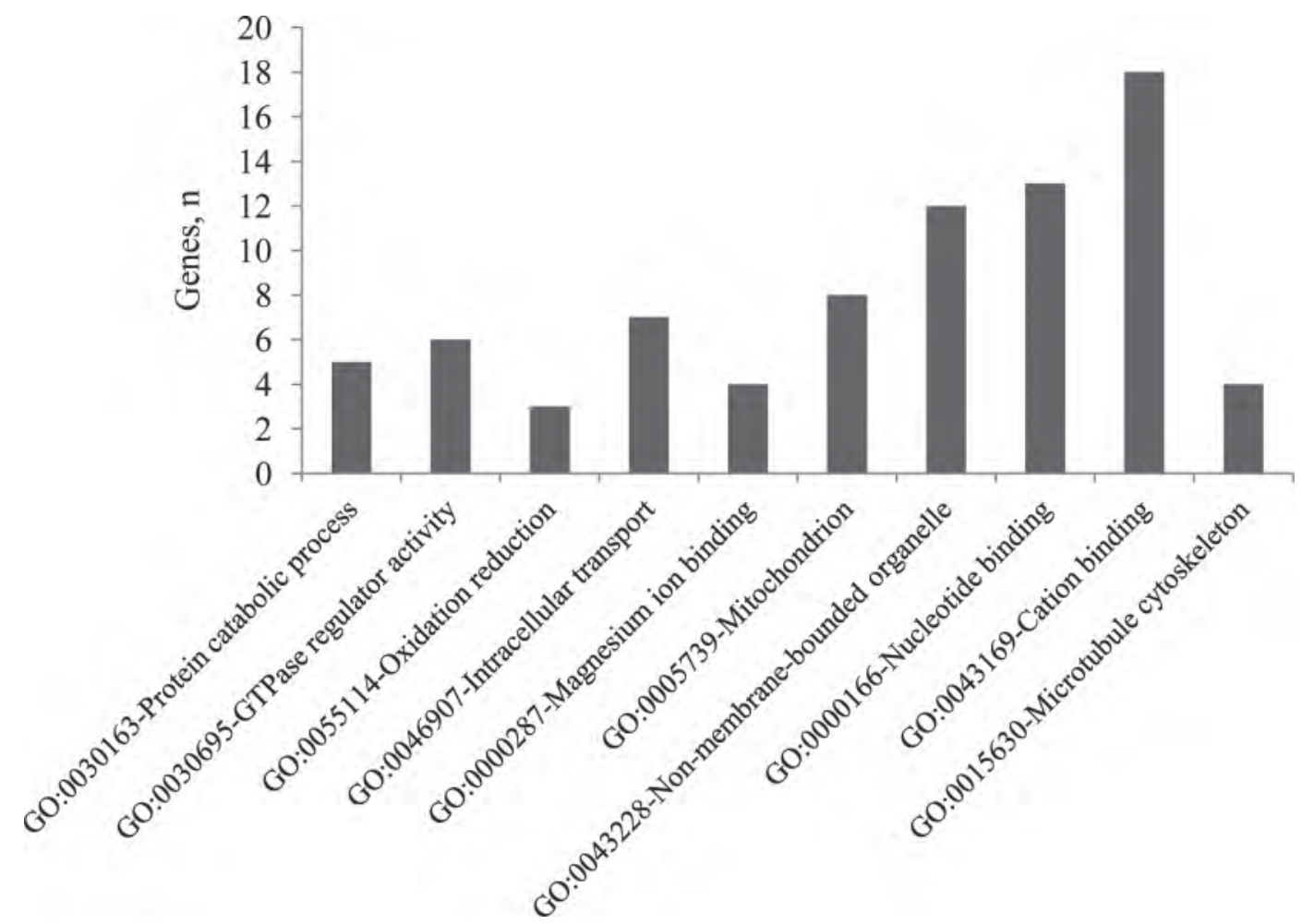

Figure 7. Enriched gene ontology (GO; http://www.geneontology.org/) terms for genes involved in the interaction between lactation and pregnancy in the endometrium of cows. Terms shown are those that best represented the terms within each cluster. Order of significance is displayed from left to right of the figure (Supplement 5; http://www.journalofdairyscience.org/). No bars represent an enrichment score for the cluster $\geq 1.3$ (Supplement 2; http://www.journalofdairyscience.org/).

caused specifically by lactation. Nonetheless, it is not surprising that an event such as lactation could promote an imbalance in the immune system in the periimplantation period, with potential negative effects on maintenance of the conceptus. Several chemokines and cytokines are responsible for the stimulation of B-lymphocyte plasma cells to produce antibodies; however, conclusions on how lactation affects immunoglobulin production are unclear at this point and require further investigation.

The gene TRD encodes for a cell receptor delta locus associated specifically with the $\gamma \delta \mathrm{T}$ cell, which is an important cell regulating the embryo-maternal relationship (Szekeres-Bartho et al., 2001). There is a greater presence of $\gamma \delta \mathrm{T}$ cells in the uterus of pregnant compared with nonpregnant mice (Heyborne et al., 1992). However, in cows there is no indication of a population increase of $\gamma \delta$ cell receptor on d 33 to 34 of pregnancy (Oliveira and Hansen, 2008). The $\gamma \delta \mathrm{T}$ cells, unlike the $\alpha \beta \mathrm{T}$ cells, are not major histocompatibility complex (MHC)-restricted and can recognize unprocessed antigens without presentation by MHC molecules; thus, $\gamma \delta$ $\mathrm{T}$ cells are likely to interact with the conceptus during pregnancy because $\gamma \delta \mathrm{T}$ cells need the conceptus for activation. In humans, $\gamma \delta \mathrm{T}$ cells have been associated with the production of IL-10 and transforming growth factor $\beta 1$ (TGFB1; Nagaeva et al., 2002; MinchevaNilsson, 2003), classical immunosuppressive molecules indicative that $\gamma \delta \mathrm{T}$ cells are immunomodulatory during pregnancy. According to our results, pregnancy on $\mathrm{d}$ 17 of gestation probably did not change the population of $\gamma \delta \mathrm{T}$ cells as indicated by the same gene expression of $\gamma \delta$ cell receptor in cyclic and pregnant cows, but a clear imbalance on its expression (2.07-fold increase) caused by lactation was created with possible effects on fertility.

The changes in the endometrium transcriptome caused by lactation described above have the potential to affect mechanisms that are often observed in pregnant uteri. Among many immune-related genes affected only by pregnancy, some exemplify the notion that the uterus is searching for an immunologically balanced environment necessary for a successful implantation. For instance, the chemokine signaling pathway (Figure 11) is a classical pathway affected by type 1 IFN (Stark et al., 1998). The chemokine $C X C L 10$, which was upregulated more than 11-fold in pregnant cows in the current study, is described as a promoter of trophoblast growth, 

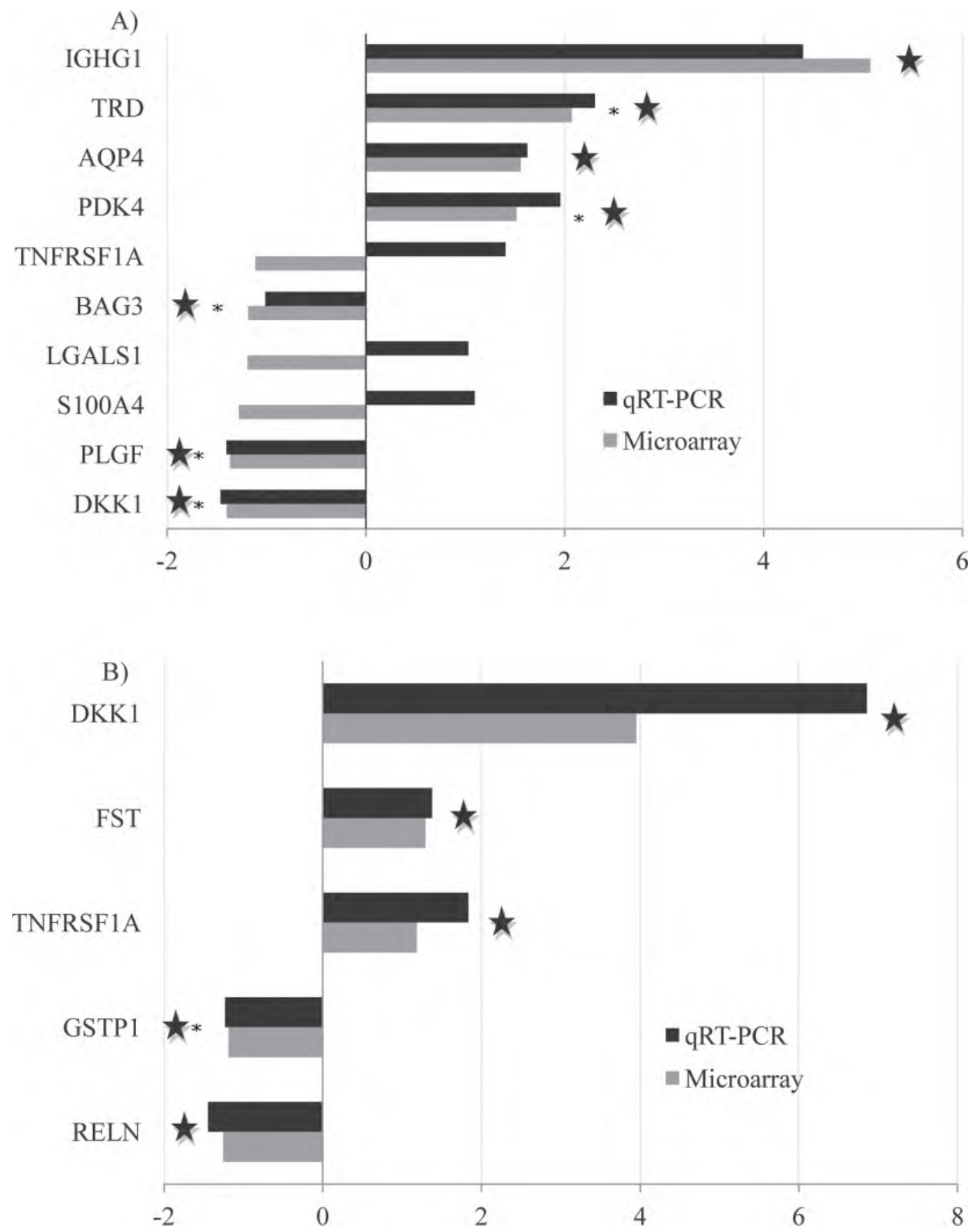

Figure 8. Validation of the microarray results using quantitative reverse transcription (qRT)-PCR of the expression of selected transcripts that were initially found up- or downregulated in response to effects of lactation (A; lactating vs. nonlactating) or pregnancy status (B; pregnant vs. cyclic). Beside each bar, the star denotes that $P$-values from the microarray and qRT-PCR analyses were in agreement. Genes are as defined in Table 1.

migration, and adhesion (Nagaoka et al., 2003), but it also regulates inflammatory and immune responses with a strong chemotactic activity toward $\mathrm{T}$ helper 1-lymphocytes, eosinophils, monocytes, and dendritic cells (Taub et al., 1993). In the current study and others (Lobo et al., 2004), many genes of the complement pathway were upregulated by pregnancy $(C 1 Q A, C 1 Q B$, $C 1 Q C, C 2, C F B, C F P$ ), a proinflammatory B-lymphocyte stimulated reaction probably needed to provide the developing embryo with some protection within an uterine environment that on d 17 of estrous cycle or pregnancy is driven by the immunosuppressive effects 


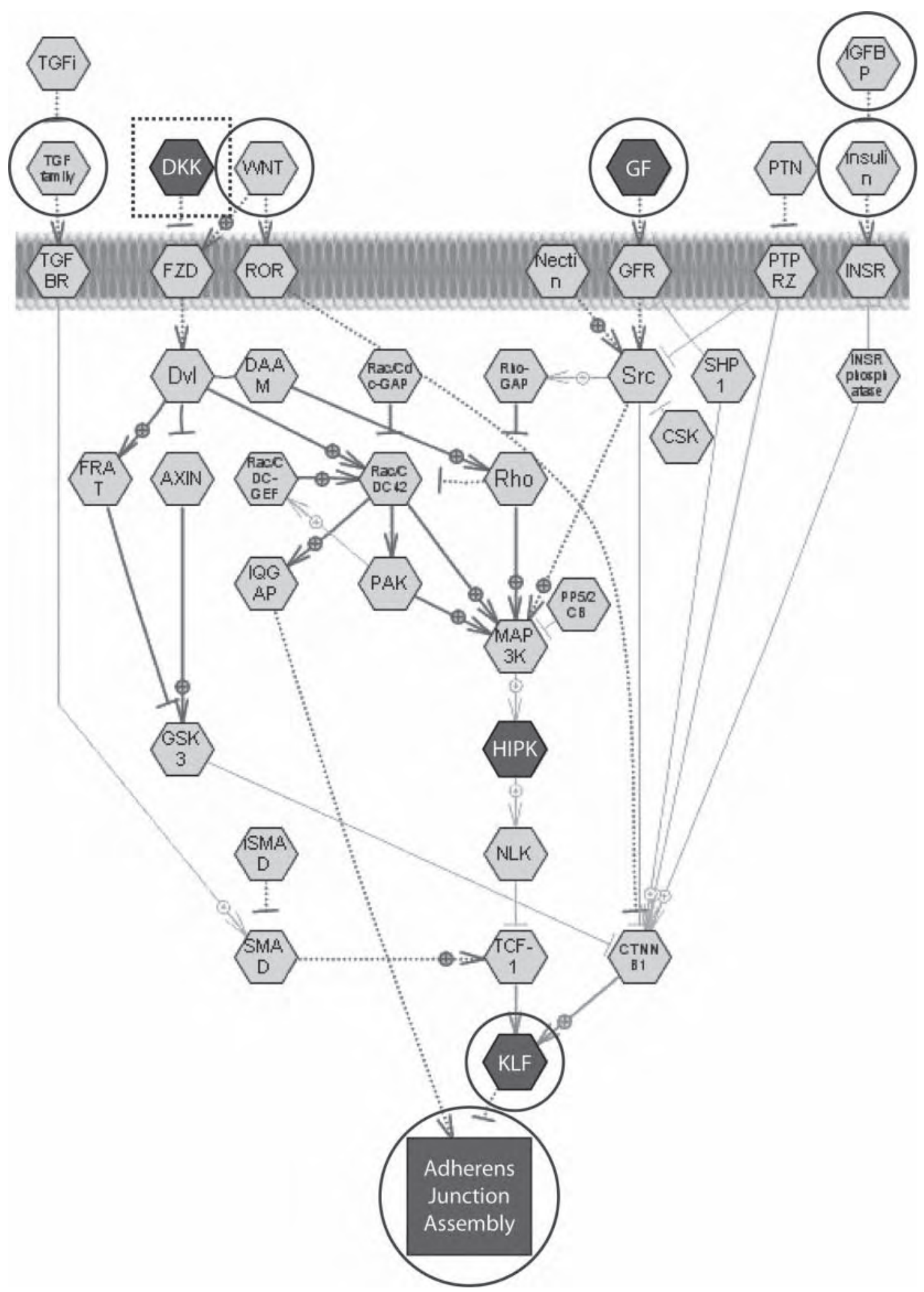

Figure 9. Schematic picture of a major pathway (adherens junction assembly) thought to be affected by lactation and pregnancy in the endometrium of cows. Items in dark gray contains genes downregulated by lactation, whereas items surrounded by a dashed square (upregulated) and a circle (downregulated) are regulated by pregnancy. 


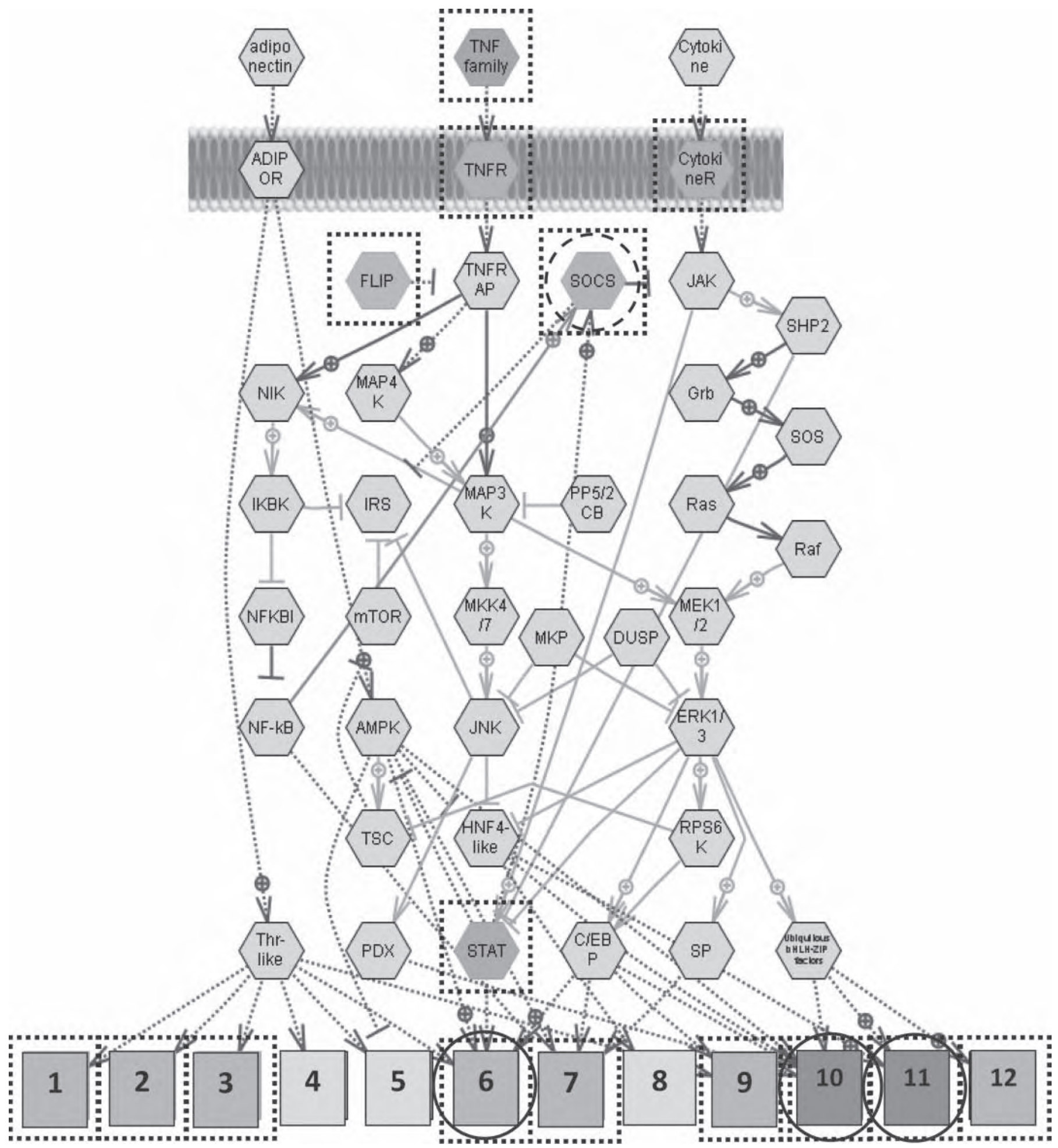

Figure 10. Schematic picture of a major pathway (adipocytokine signaling) affected by lactation and pregnancy in the endometrium of cows. Items surrounded by a dashed square contains genes upregulated by pregnancy, whereas items surrounded by a dashed circle (upregulated) and a continuous circle (downregulated) are regulated by lactation. $1=$ cholesterol metabolism; $2=$ fatty acids import; $3=$ lipid degradation; $4=$ peroxisome division; $5=$ fatty acid biosynthesis; $6=$ fatty acid oxidation; $7=$ glucose import; $8=$ bile acid metabolism; $9=$ tricarboxylic acid cycle; $10=$ glucose metabolism; $11=$ lipid transport; $12=$ triacylglycerol degradation. 


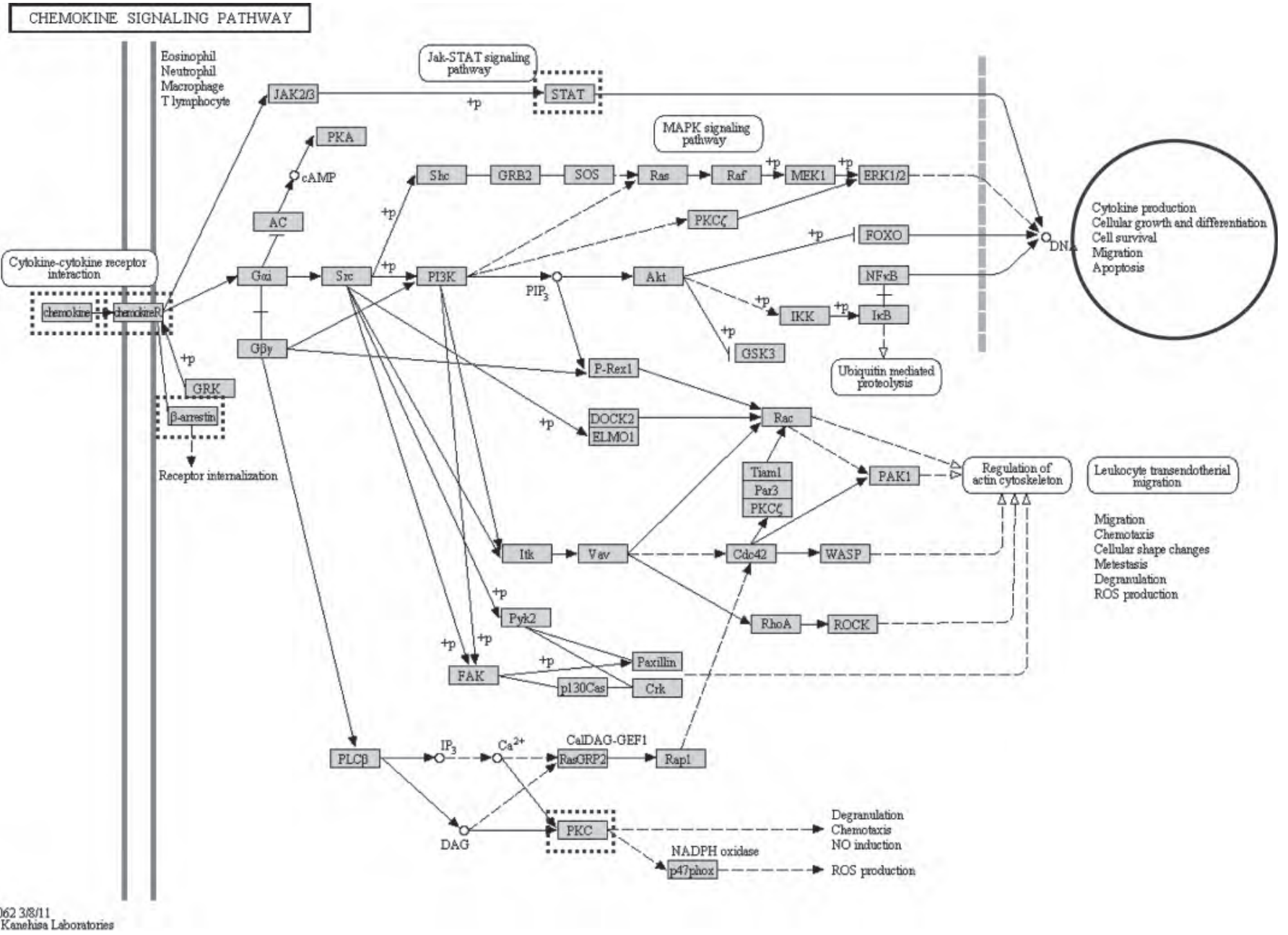

Figure 11. Schematic picture of a major pathway (KEGG pathway hsa04062: chemokine signaling pathway) affected by pregnancy in the endometrium of cows. Gray boxes represent gene products (mostly proteins). Open small circles represent other consequential down-stream effector molecules, mostly chemical compounds (i.e., cAMP, cyclic adenosine monophosphate; PIP3, phosphatidylinositol $(3,4,5)$-trisphosphate; IP3, inositol trisphosphate; DAG, diacylglycerol, and $\mathrm{Ca}^{2+}$ ). Solid lines with solid arrowheads indicate activation. Solid lines with a perpendicular line at the end indicate inhibition. Dashed lines with solid arrowheads indicate indirect effect. Dashed lines with open arrowheads indicate link to another pathway map. Two parallel vertical solid gray lines indicate the cellular membrane. Vertical dashed gray line indicates the nuclear membrane. Items surrounded by a dashed rectangle represent genes upregulated by pregnancy. Item surrounded by a circle represents the biological functions mostly affected by this pathway. Used with permission of Dr. M. Kanehisa, Institute for Chemical Research, Kyoto University, Kyoto, Japan.

of progesterone. A direct regulator of the complement system is pentraxin-related gene (PTX3), which was highly upregulated by pregnancy in the current study and has the ability to bind $\mathrm{C} 1 \mathrm{Q}$ and regulate the classical complement pathway cascade (Nauta et al., 2003; Popovici et al., 2008). The uterine serpins SERPING1 or SERPINA14 were also upregulated in the current study and could serve as immune suppressors against the complement-mediated immune responses. In sheep, SERPINA14 can block lymphocyte proliferation in vitro, natural killer cell activity in vitro and in vivo, and T-cell dependent antibody production in vivo (Padua and Hansen, 2010). Another gene upregulated (64-fold increase) in pregnant cows that could also have an immunomodulatory activity is indoleamine 2,3-dioxygenase (INDO or IDO). Recently, an 18-fold increase in IDO mRNA was observed in d-18 pregnant heifers, and a decrease in endometrial L-tryptophan and an increase in L-kynurenine were observed from d 12 to 18 in pregnant heifers (Groebner et al., 2011). Results from the current study indicate that the immune system is probably the most affected system in the endometrium when the conceptus is present. A vast number of genes with distinct immune functions (i.e., pro- and antiinflammatory) may serve to create a uterine environment that is sufficiently protected against viral and bacterial infections but still tolerant enough to accept the implantation of the embryo. Lactation is likely to affect 
this balanced immune environment in the endometrium with potential negative effects on embryo survivability.

\section{Cell Adhesion, Tissue Remodeling, and the Canonical Wnt Signaling Pathway}

The genes most downregulated by pregnancy were related to cell adhesion and tissue remodeling. In the GO analysis, cell adhesion (GO:0007155), extracellular matrix (GO:0031012), basement membrane (GO:0005604), and fibrillar collagen (GO:0005583) were among the terms that represented the most significant clusters of biological functions, molecular functions, and cellular components.

The cadherin $C D H 1$ or E-cadherin was affected by pregnancy and, unlike other cadherins, was upregulated in the present study. E-Cadherin is a transmembrane cell surface molecule that is involved in calcium-dependent cell-to-cell adhesion of epithelial cells (Takeichi, 1988). It interacts with $\beta$-catenin, which, in addition to having a role in cell adhesion, functions as an intracellular signaling molecule in the canonical Wnt pathway (Willert and Nusse, 1998). The Wnt signaling pathway is implicated in cell polarity, proliferation, differentiation, and junctional complexes, including CDH1 (Jamora et al., 2003; Karner et al., 2006). In the current study, WNT2, GSK3B, MSX1 were all downregulated (CTNNB1 had a numerical decrease in expression only) by pregnancy, findings similar to those in preimplantation endometrium in sheep (Satterfield et al., 2008). The cascade of the Wnt signaling pathway represented by WNT2, GSK3B, CTNNB1, and MSX1 was in fact downregulated on d 17 of pregnancy, which indicates an important feature of bovine uterine regulation in preparation to accommodate the conceptus. Furthermore, a pregnancy upregulation (almost 4-fold) of dickkopf homolog 1 (DKK1), a secreted inhibitor of Wnt signaling (Glinka et al., 1998), may be the main force contributing to the downregulation of the canonical Wnt pathway. Interestingly, $C D H 1$ was upregulated in pregnancy, indicating that $C D H 1$ is probably under the influence of another signaling pathway and that perhaps other cadherins and claudins, such as $C D H 2$, CDH11, CDH13, and CLDN10, are targets of the Wnt signaling pathway in cattle. In addition to its function in the endometrium, $D K K 1$ of endometrial origin could go to the lumen and affect embryo development because of its function in head and limb development (Grotewold and Rüther, 2002; Nie, 2005; Lieven et al., 2010). The fact that we observed a downregulation of DKK1 by lactation (2-fold downregulated) that counters the positive effect of pregnancy on $D K K 1$ expression indicates a powerful candidate gene mediating the effects of lactation on endometrium transcriptome. Improper amounts of DKK1 to block the Wnt pathway in the uterus and in the conceptus at specific times (such as on d 17 of gestation) could lead to suboptimal embryo development and partly explain the large embryonic losses observed in lactating dairy cows. Another gene regulated by pregnancy and lactation and their interaction was reelin $(R E L N)$; it was downregulated in lactating pregnant cows compared with lactating cyclic cows, but was not altered by pregnancy status in nonlactating cows. The $R E L N$ gene encodes a secretory serine protease (a glycoprotein) that guides neurons and radial glial cells to their correct positions during brain development in the embryo (Fatemi, 2005). Lactating pregnant cows had a decrease in RELN expression to about half of what was observed in lactating cyclic cows, demonstrating a possible imbalance and perhaps lower availability of this protein with potential effects on embryo differentiation and development. It is interesting to note that DKK1 and RELN can both utilize the same receptor family (lipoprotein receptors, LPR), and both have implications in brain formation during embryo development.

Other genes related to cell adhesion were highly downregulated by pregnancy alone. Genes such as CD44, cadherins (CDH2, CDH11, CDH13), claudins (CLDN5, CLDN10), and collagens (COL3A1, COL5A3, COL12A1, COL13A1, COL27A1) were among the most important transcripts downregulated by pregnancy, whereas CDH1, TIMP2, CLDN4, LGALS9, and $L G A L S 3 B P$ were strongly upregulated. The downregulation of cadherins, claudins, and collagens indicates a strong remodeling of the endometrium tissue, perhaps to accommodate the changes necessary for embryo development, such as vascularization, uterine gland remodeling, cell proliferation, migration, and even the permeability of the epithelium (Tsukita and Furuse, 2002). Satterfield et al. (2008), when studying the effect of pregnancy and progesterone on the Wnt signaling pathway, observed downregulation of genes related to tight junctions in the preimplantation period of the ovine uterus. Those authors suggest that the loss of epithelial tight junctions before elongation may be to increase the availability of serum- or stromal-derived molecules within the uterine lumen that stimulate embryo growth and elongation (Satterfield et al., 2008).

Genes related to vasculature development (GO:0001944) were downregulated by pregnancy, most notably VEGFA. Angiopoietin-like 2 (ANGPTL2), known to regulate endothelial cell growth (Morisada et al., 2006), was downregulated by pregnancy in the current study and previously described as a possible regulator of angiogenesis during the estrous cycle (Mitko et al., 2008). Most reports indicate a vasculature development during pregnancy and toward estrus during 
the estrous cycle (Greiss and Anderson, 1969; Mitko et al., 2008). However, little information is known about the vasculature remodeling on $\mathrm{d} 17$ of gestation in the bovine. Lactation, for instance, downregulated placental growth factor ( $P l G F$ or $P G F$ ), which is positively involved in angiogenesis and partly regulated by $V E G F$ via MAPK signaling pathway in humans (Zhao et al., 2004). Angiogenesis is probably a dynamic process as gestation progresses, but the results from this study indicate that, near implantation, both pregnancy and lactation seem to downregulate this process. Whether the downregulation of $P l G F$ by lactation has an additive negative effect on vascularization and negatively affects uterine function and embryo development remains unclear.

\section{Carbohydrate, FA, and AA Metabolism}

Another major set of GO terms regulated by pregnancy was related to transport and metabolism of carbohydrate, lipids, and protein. Carboxylic acid metabolic process (GO:0019752), cellular lipid metabolic process (GO:0044255), cellular amino acid and derivative metabolic process (GO:0006519), fatty acid metabolic process (GO:0006631), and glucose metabolic process (GO:0006006) were upregulated by pregnancy. These coordinated gene expression responses indicate that the uterus is in a high metabolic state to support anabolic and catabolic activities during the period of conceptus implantation. A great number of transcripts were responsive to pregnancy at $\mathrm{d} 17$ in relation to lipid metabolism and transport (FABP3, ACAA1, ACAT2, CPT1B, CPT1C, CRAT, SLC27A2), glucose homeostasis and transport [LOC614107 (similar to hexokinase II), PCK2, SLC2A1, PFKM, PFKP, PGM5, PDK2, $G C K]$, monocarboxylic acid transporters (SLC16A1, SLC16A3, SLC16A13), oligopeptide transporter (SLC15A1), neutral amino acid transporter (SLC1A5), mitochondrial carriers (SLC25A1, SLC25A3, SLC25A4, SLC25A5, SLC25A12, SLC25A25, SLC25A28, SLC25A30, SLC25A33, SLC25A37, SLC25A38), phosphate transporter (SLC20A1), sodium, potassium, chloride transporter (SLC12A2), and cation transport (SLC22A17).

Genes related to protein transport, generation of precursor metabolites and energy, glucose metabolism, and FA biosynthetic processes, such as DGAT2, MGOAT1, $M V K, A D S L 5$, and SLC27A6, were upregulated in the endometrium of d 7 compared with d 5 of the estrous cycle (Forde et al., 2009). Mitko et al. (2008) found an overrepresentation of genes involved in nutritional support of the embryo during diestrus, including several transporters such as SLC1A1 (glutamate), SLC11A2 (metal ion), and SLC16A1 (monocarboxylate), indicat- ing that transporter molecules are actively upregulated as the estrous cycle progresses, possibly adjusting to metabolic needs of the elongating embryo. Results also indicate that not only are transporters of substrates more available on d 17 of pregnancy in endometrial cells but they are all upregulated in association with a large number of genes related to glycolysis such as LOC614107 (similar to hexokinase II), hexokinase 4 $(G C K)$, phosphoenolpyruvate carboxykinase 2 (PCK2), phosphofructokinase $(P F K)$, and phosphoglucomutase 5 (PGM5). Interestingly, the only gene linked to glycolysis and affected (upregulated) by lactation was pyruvate dehydrogenase kinase $(P D K 4)$, which was not affected by pregnancy. It is involved in the reduction of glucose utilization by inhibiting pyruvate dehydrogenase, thus reducing the conversion of pyruvate as an energy source through the citric acid cycle (Sugden and Holness, 2006). Lactation also decreased a carbohydrate transporter $(S L C 35 A 4)$ and another transporter related to zinc (SLC39A13), which could partially impair the utilization of glucose by the endometrium and negatively affect pregnancy.

The metabolism of FA was notably upregulated in pregnancy by acetyl-coenzyme A acyltransferase 1 (ACAA1), acetyl-coenzyme $\mathrm{A}$ acetyltransferase 2 (ACAT2), carnitine palmitoyltransferase 1B $(C P T 1 B)$, and $(C P T 1 C) 1 \mathrm{C}$, carnitine acetyltransferase $(C R A T)$, and fatty acid transporter (SLC27A2). Both ACAA1 and $A C A T 2$ are involved in lipid biosynthesis and are capable of regulating synthesis of cholesterol, cholesterol ester, and possibly steroids. Both $C P T 1 B$ and $C P T 1 C$ are proteins responsible for the transport of FA across the mitochondrial membrane for FA metabolism, including $\beta$-oxidation for energy generation. Functions of energy generation and lipid biosynthesis controlled by genes stimulated by pregnancy is in accordance with the uterine environment on d 17 of pregnancy, which is characterized by tissue remodeling, high energy utilization, and necessity of substrates for the uterus and histiotrophic support of the conceptus.

\section{CONCLUSIONS}

Analyzing the effect of lactation on the endometrium unveiled possible candidate genes responsible for sub-fertility in lactating dairy cows. Several genes (FCGRT, IGHG1, IGLL, and TRD) were upregulated by lactation but not altered by pregnancy. These genes indicate a possible increase in B-lymphocyte and $\gamma \delta$ T-cell activity that could negatively affect the fine immunological balance of the uterus necessary to accept the semi-allograph embryo. In addition, lactation affected DKK1 and RELN, 2 genes involved with embryonic neural and limb development, by counter- 
ing the effects of pregnancy on these genes. The Wnt signaling pathway was downregulated by pregnancy, and the increase in $D K K 1$ by lactation may prove an important process that regulates embryonic loss in lactating dairy cows. The regulation of different immune functions seems to be the most important event in the d 17 pregnant endometrium as observed by the several genes and GO terms related to the immune system, and the current study suggests that lactation disturbs some of these mechanisms. Cell adhesion (represented by cadherins, claudins, collagens, and L-galectins) was a function mostly downregulated by pregnancy at this stage, which may indicate a strong tissue remodeling as well as a window of time that facilitates the flow of substrates to the uterine lumen to support the elongating embryo. The implication that lactation acts on the Wnt signaling pathway also indicates an interference of lactation on remodeling of the endometrium. In addition, the effect of lactation on RELN reinforces the potential impact of lactational status on embryonic differentiation and development. Because of the activity in endometrial tissue on d 17 of gestation, genes related to carbohydrate, lipid, and AA metabolism and transport are upregulated by pregnancy, but upregulation of $P D K 4$ by lactation indicates that lactation exerted a negative effect on glucose homeostasis.

\section{ACKNOWLEDGMENTS}

The authors thank Pfizer Animal Health (New York, NY) for grant support and the staff of the University of Florida Dairy Unit (Gainesville) and the Interdisciplinary Center for Biotechnology Research at the University of Florida for invaluable technical support. Technical assistance of I. M. Alvarez, K. A. Pennington, T. M. Rodina, F. N. Cooke, and Q. E. Yang, from the Department of Animal Sciences at University of Florida, is appreciated for collection of samples and qRT-PCR analyses.

\section{REFERENCES}

Austin, K. J., B. M. Bany, E. L. Belden, L. A. Rempel, J. C. Cross, and T. R. Hansen. 2003. Interferon-stimulated gene 15 (isg15) expression is up-regulated in the mouse uterus in response to the implanting conceptus. Endocrinology 145:3107-3113.

Bauersachs, S., S. E. Ulbrich, K. Gross, S. E. Schmidt, H. H. Meyer, H. Wenigerkind, M. Vermehren, F. Sinowatz, H. Blum, and E. Wolf. 2006. Embryo-induced transcriptome changes in bovine endometrium reveal species-specific and common molecular markers of uterine receptivity. Reproduction 132:319-331.

Bazer, F. W., T. E. Spencer, and G. A. Johnson. 2009. Interferons and uterine receptivity. Semin. Reprod. Med. 27:90-102.

Bolstad, B. M., R. A. Irizarry, M. Astrand, and T. P. Speed. 2003. A comparison of normalization methods for high density oligonucleotide array data based on variance and bias. Bioinformatics 19:185-193.
Chagas e Silva, J., L. Lopes da Costa, and J. Robalo Silva. 2002 Plasma progesterone profiles and factors affecting embryo-fetal mortality following embryo transfer in dairy cattle. Theriogenology 58:51-59.

Chen, Y., E. Antoniou, Z. Liu, L. B. Hearne, and R. M. Roberts. 2007. A microarray analysis for genes regulated by interferon-tau in ovine luminal epithelial cells. Reproduction 134:123-135.

Cooke, F. N., K. A. Pennington, Q. Yang, and A. D. Ealy. 2009. Several fibroblast growth factors are expressed during pre-attachment bovine conceptus development and regulate interferon-tau expression from trophectoderm. Reproduction 137:259-269.

Fatemi, S. H. 2005. Reelin glycoprotein: Structure, biology and roles in health and disease. Mol. Psychiatry 10:251-257.

Forde, N., F. Carter, T. Fair, M. A. Crowe, A. C. Evans, T. E. Spencer, F. W. Bazer, R. McBride, M. P. Boland, P. O'Gaora, P. Lonergan, and J. F. Roche. 2009. Progesterone-regulated changes in endometrial gene expression contribute to advanced conceptus development in cattle. Biol. Reprod. 81:784-794.

Forde, N., F. Carter, T. E. Spencer, F. W. Bazer, O. Sandra, N. Mansouri-Attia, L. A. Okumu, P. A. McGettingan, J. P. Mehta, R. McBride, P. O'Gaora, J. F. Roche, and P. Lonergan. 2011. Conceptusinduced changes in endometrial transcriptome: How soon does the cow know she is pregnant? Biol. Reprod. 85:144-156. http:// dx.doi.org/biolreprod.110.090019.

Forde, N., T. E. Spencer, F. W. Bazer, G. Song, J. F. Roche, and P. Lonergan. 2010. Effect of pregnancy and progesterone concentration on expression of genes encoding for transporters or secreted proteins in the bovine endometrium. Physiol. Genomics 41:53-62.

Gentleman, R. C., V. J. Carey, D. M. Bates, B. Bolstad, M. Dettling, S. Dudoit, B. Ellis, L. Gautier, Y. Ge, J. Gentry, K. Hornik, T. Hothorn, W. Huber, S. Iacus, R. Irizarry, F. Leisch, C. Li, M. Maechler, A. J. Rossini, G. Sawitzki, C. Smith, G. Smyth, L. Tierney, J. Y. Yang, and J. Zhang. 2004. Bioconductor: Open software development for computational biology and bioinformatics. Genome Biol. 5:R80.

Glinka, A., W. Wu, H. Delius, A. P. Monaghan, C. Blumenstock, and C. Niehrs. 1998. Dickkopf-1 is a member of a new family of secreted proteins and functions in head induction. Nature 391:357-362.

Greiss, F. C., and S. G. Anderson. 1969. Uterine vascular changes during the ovarian cycle. Am. J. Obstet. Gynecol. 103:629-640.

Groebner, A. E., K. Schulke, J. C. Schefold, G. Fusch, F. Sinowatz, H. D. Reichenbach, E. Wolf, H. H. Meyer, and S. E. Ulbrich. 2011. Immunological mechanisms to establish embryo tolerance in early bovine pregnancy. Reprod. Fertil. Dev. 23:619-632.

Grotewold, L., and U. Rüther. 2002. The Wnt antagonist Dickkopf-1 is regulated by Bmp signaling and c-Jun and modulates programmed cell death. EMBO J. 21:966-975.

Hansen, P. J., R. V. Anthony, F. W. Bazer, G. A. Baumbach, and R. M. Roberts. 1985. In vitro synthesis and secretion of ovine trophoblast protein-1 during the period of maternal recognition of pregnancy. Endocrinology 117:1424-1430.

Hasler, J. F. 2001. Factors affecting frozen and fresh embryo transfer pregnancy rates in cattle. Theriogenology 56:1401-1415.

Heyborne, K. D., R. L. Cranfill, S. R. Carding, W. K. Born, and R. L. O'Brien. 1992. Characterization of gamma delta T lymphocytes at the maternal-fetal interface. J. Immunol. 149:2872-2878.

Jamora, C., R. DasGupta, P. Kocieniewski, and E. Fuchs. 2003. Links between signal transduction, transcription and adhesion in epithelial bud development. Nature 422:317-322.

Karner, C., K. A. Wharton, and T. J. Carroll. 2006. Apical-basal polarity, Wnt signaling and vertebrate organogenesis. Semin. Cell Dev. Biol. 17:214-222.

Kobayashi, Y., C. K. Boyd, C. J. Bracken, W. R. Lamberson, D. H. Keisler, and M. C. Lucy. 1999. Reduced growth hormone receptor (GHR) messenger ribonucleic acid in liver of periparturient cattle is caused by a specific down-regulation of GHR 1A that is associated with decreased insulin-like growth factor I. Endocrinology 140:3947-3954.

Li, Q., M. Zhang, S. Kumar, L. J. Zhu, D. Chen, M. K. Bagchi, and I. C. Bagchi. 2001. Identification and implantation stage specific 
expression of an interferon-alpha-regulated gene in human and rat endometrium. Endocrinology 142:2390-2400.

Lieven, O., J. Knobloch, and U. Rüther. 2010. The regulation of Dkk1 expression during embryonic development. Dev. Biol. 340:256268

Lobo, S. C., S. T. Huang, A. Germeyer, C. Dosiou, K. C. Vo, S. Tulac, N. R. Nayak, and L. C. Giudice. 2004. The immune environment in human endometrium during the window of implantation. Am. J. Reprod. Immunol. 52:244-251.

Loor, J. J., R. E. Everts, M. Bionaz, H. M. Dann, D. E. Morin, R. Oliveira, S. L. Rodriguez-Zas, J. K. Drackley, and H. A. Lewin. 2007. Nutrition-induced ketosis alters metabolic and signaling gene networks in liver of periparturient dairy cows. Physiol. Genomics 32:105-116.

Lucy, M. C. 2001. Reproductive loss in high-producing dairy cattle: Where will it end? J. Dairy Sci. 84:1277-1293.

Mansouri-Attia, N., J. Aubert, P. Reinauld, C. Giraud-Delville, G. Taghouti, L. G. Alio, R. E. Everts, S. Degrelle, C. Richard, I. Hue, X. Yang, X. C. Tian, H. A. Lewin, J. P. Renard, and O. Sandra. 2009. Gene expression profiles of bovine caruncular and intercaruncular endometrium at implantation. Physiol. Genomics 39:14-27.

Mincheva-Nilsson, L. 2003. Pregnancy and gamma/delta T cells: Taking on the hard questions. Reprod. Biol. Endocrinol. 1:120.

Mitko, K., S. E. Ulbrich, H. Wenigerkind, F. Sinowatz, H. Blum, E. Wolf, and S. Bauersachs. 2008. Dynamic changes in messenger RNA profiles of bovine endometrium during the oestrous cycle. Reproduction 135:225-240.

Morisada, T., Y. Kubota, T. Urano, T. Suda, and Y. Oike. 2006. Angiopoietins and angiopoietin-like proteins in angiogenesis. Endothelium 13:71-79.

Nagaeva, O., L. Jonsson, and L. Mincheva-Nilsson. 2002. Dominant IL-10 and TGF-beta mRNA expression in gamma-delta T cells of human early pregnancy decidua suggests immunoregulatory potential. Am. J. Reprod. Immunol. 48:9-17.

Nagaoka, K., H. Nojima, F. Watanabe, K. T. Chang, R. K. Christenson, S. Sakai, and K. Imakawa. 2003. Regulation of blastocyst migration, apposition, and initial adhesion by a chemokine, interferon gamma-inducible protein $10 \mathrm{kDa}$ (IP-10), during early gestation. J. Biol. Chem. 278:29048-29056.

Nauta, A. J., B. Bottazzi, A. Mantovani, G. Salvatori, U. Kishore, W. J. Schwaeble, A. R. Gingras, S. Tzima, F. Vivanco, J. Egido, O. Tijsma, E. C. Hack, M. R. Daha, and A. Roos. 2003. Biochemical and functional characterization of the interaction between pentraxin 3 and C1q. Eur. J. Immunol. 33:465-473.

Nie, X. 2005. Dkk1, -2, and -3 expression in mouse craniofacial development. J. Mol. Histol. 36:367-372.

Oliveira, L. J., and P. J. Hansen. 2008. Deviations in populations of peripheral blood mononuclear cells and endometrial macrophages in the cow during pregnancy. Reproduction 136:481-490.

Padua, M. B., and P. J. Hansen. 2010. Evolution and function of the uterine serpins (SERPINA14). Am. J. Reprod. Immunol. 64:265274

Popovici, R. M., M. S. Krause, J. Jauckus, A. Germeyer, I. S. Brum, C. Garlanda, T. Strowitzki, and M. von Wolff. 2008. The long pentraxin PTX3 in human endometrium: Regulation by steroids and trophoblast products. Endocrinology 149:1136-1143.

Pretheeban, T., M. Gordon, R. Singh, R. Perera, and R. Rajamahendran. 2009. Differential mRNA expression in in vivo produced pre-implantation embryos of dairy heifers and mature cows. Mol. Reprod. Dev. 76:1165-1172.

Rizos, D., F. Carter, U. Besenfelder, V. Havlicek, and P. Lonergan. 2010. Contribution of the female reproductive tract to low fertility in postpartum lactating dairy cows. J. Dairy Sci. 93:1022-1029.

Roberts, R. M., Y. Chen, T. Ezashi, and A. M. Walker. 2008. Interferons and the maternal-conceptus dialog in mammals. Semin. Cell Dev. Biol. 19:170-177.

Santos, J. E. P., W. W. Thatcher, R. C. Chebel, R. L. A. Cerri, and K. N. Galvão. 2004. The effect of embryonic death rates in cattle on the efficacy of estrus synchronization programs. Anim. Reprod. Sci. 82-83:513-535.

Sartori, R., M. R. Bastos, and M. C. Wiltbank. 2010. Factors affecting fertilisation and early embryo quality in single- and superovulated dairy cattle. Reprod. Fertil. Dev. 22:151-158.

Sartori, R., G. J. Rosa, and M. C. Wiltbank. 2002. Fertilization and early embryonic development in heifers and lactating cows in summer and lactating and dry cows in winter. J. Dairy Sci. 85:28132822 .

Satterfield, M. C., G. Song, K. Hayashi, F. W. Bazer, and T. E. Spencer. 2008. Progesterone regulation of the endometrial WNT system in the ovine uterus. Reprod. Fertil. Dev. 20:935-946.

Smyth, G. K. 2004. Linear models and empirical Bayes methods for assessing differential expression in microarray experiments. Stat. Appl. Genet. Mol. Biol. 3:e3.

Spencer, T. E., and F. W. Bazer. 2004. Conceptus signals for establishment and maintenance of pregnancy. Reprod. Biol. Endocrinol. $2: 49$.

Spencer, T. E., O. Sandra, and E. Wolf. 2008. Genes involved in conceptus-endometrial interactions in ruminants: Insights from reductionism and thoughts on holistic approaches. Reproduction 135:165-179.

Stark, G. R., I. M. Kerr, B. R. Williams, R. H. Silverman, and R. D. Schreiber. 1998. How cells respond to interferons. Annu. Rev. Biochem. 67:227-264.

Sugden, M. C., and M. J. Holness. 2006. Mechanisms underlying regulation of the expression and activities of the mammalian pyruvate dehydrogenase kinases. Arch. Physiol. Biochem. 112:139-149.

Szekeres-Bartho, J., A. Barakonyi, E. Miko, B. Polgar, and T. Palkovics. 2001. The role of gamma/delta T cells in the feto-maternal relationship. Semin. Immunol. 13:229-233.

Takeichi, M. 1988. The cadherins: Cell-cell adhesion molecules controlling animal morphogenesis. Development 102:639-655.

Taub, D. D., A. R. Lloyd, K. Conlon, J. M. Wang, J. R. Ortaldo, A. Harada, K. Matsushima, D. J. Kelvin, and J. J. Oppenheim. 1993. Recombinant human interferon-inducible protein 10 is a chemoattractant for human monocytes and $\mathrm{T}$ lymphocytes and promotes T cell adhesion to endothelial cells. J. Exp. Med. 177:1809-1814.

Thatcher, W. W., P. J. Hansen, T. S. Gross, S. D. Helmer, C. Plante, and F. W. Bazer. 1989. Antiluteolytic effects of bovine trophoblast protein-1. J. Reprod. Fertil. Suppl. 37:91-99.

Thompson, I. M., R. L. A. Cerri, I. H. Kim, A. D. Ealy, P. J. Hansen, C. R. Staples, and W. W. Thatcher. 2012. Effects of lactation and pregnancy on metabolic and hormonal responses and conceptus and endometrial gene expression of Holstein dairy cattle. J. Dairy Sci. 95:5645-5656. http://dx.doi.org/10.3168/jds.2011-5113.

Tsukita, S., and M. Furuse. 2002. Claudin-based barrier in simple and stratified cellular sheets. Curr. Opin. Cell Biol. 14:531-536.

Walker, C. G., S. Meier, M. D. Littlejohn, K. Lehnert, J. R. Roche, and M. D. Mitchell. 2010. Modulation of the maternal immune system by the pre-implantation embryo. BMC Genomics 11:474.

Wathes, D. C., M. Fenwick, Z. Cheng, N. Bourne, S. Llewellyn, D. G. Morris, D. Kenny, J. Murphy, and R. Fitzpatrick. 2007. Influence of negative energy balance on cyclicity and fertility in the high producing dairy cows. Theriogenology 68:232-241.

Willert, K., and R. Nusse. 1998. Beta-catenin: A key mediator of Wnt signaling. Curr. Opin. Genet. Dev. 8:95-102.

Wilson, R. D., P. M. Fricke, M. L. Leibfried-Rutledge, J. J. Rutledge, C. M. Penfield, and K. A. Weigel. 2006. In vitro production of bovine embryos using sex-sorted sperm. Theriogenology 65:10071015.

Wiltbank, M. C., H. Lopez, R. Sartori, S. Sangsritavong, and A. Gumen. 2006. Changes in reproductive physiology of lactating dairy cows due to elevated steroid metabolism. Theriogenology 65:1729.

Zhao, B., J. Cai, and M. Boulton. 2004. Expression of placenta growth factor is regulated by both VEGF and hyperglycaemia via VEGFR-2. Microvasc. Res. 68:239-246. 